\title{
Differential proteomic analysis of grapevine leaves by iTRAQ reveals responses to heat stress and subsequent recovery
}

\author{
Guo-Tian Liu ${ }^{1,2 \dagger}$, Ling Ma ${ }^{1,2+}$, Wei Duan ${ }^{1}$, Bai-Chen Wang ${ }^{3}$, Ji-Hu Li ${ }^{1,2}$, Hong-Guo Xu , Xue-Qing Yan ${ }^{4}$, \\ Bo-Fang Yan ${ }^{1,2}$, Shao-Hua Li ${ }^{1,5}$ and Li-Jun Wang ${ }^{1 *}$
}

\begin{abstract}
Background: High temperature is a major environmental factor limiting grape yield and affecting berry quality. Thermotolerance includes the direct response to heat stress and the ability to recover from heat stress. To better understand the mechanism of the thermotolerance of Vitis, we combined a physiological analysis with iTRAQ-based proteomics of Vitis vinifera cv Cabernet Sauvignon, subjected to $43^{\circ} \mathrm{C}$ for $6 \mathrm{~h}$, and then followed by recovery at $25 / 18^{\circ} \mathrm{C}$.

Results: High temperature increased the concentrations of TBARS and inhibited electronic transport in photosynthesis apparatus, indicating that grape leaves were damaged by heat stress. However, these physiological changes rapidly returned to control levels during the subsequent recovery phase from heat stress. One hundred and seventy-four proteins were differentially expressed under heat stress and/or during the recovery phase, in comparison to unstressed controls, respectively. Stress and recovery conditions shared 42 proteins, while 113 and 103 proteins were respectively identified under heat stress and recovery conditions alone. Based on MapMan ontology, functional categories for these dysregulated proteins included mainly photosynthesis (about 20\%), proteins (13\%), and stress (8\%). The subcellular localization using TargetP showed most proteins were located in the chloroplasts (34\%), secretory pathways (8\%) and mitochondrion (3\%).

Conclusion: On the basis of these findings, we proposed that some proteins related to electron transport chain of photosynthesis, antioxidant enzymes, HSPs and other stress response proteins, and glycolysis may play key roles in enhancing grapevine adaptation to and recovery capacity from heat stress. These results provide a better understanding of the proteins involved in, and mechanisms of thermotolerance in grapevines.
\end{abstract}

Keywords: Cabernet sauvignon, Heat stress, iTRAQ, Photosynthesis, Proteomics, Recovery

\section{Background}

Temperature is one of the pivotal factors influencing plant growth and development. Both yield and quality are reduced when the temperature is above or below optimal levels [1]. The IPCC (Intergovernmental Panel on Climate Change) forecasts that the extreme annual daily maximum temperature (i.e., return value) will likely increase by about $1-3^{\circ} \mathrm{C}$ by mid-twenty-first century

\footnotetext{
*Correspondence: ljwang@ibcas.ac.cn

${ }^{\dagger}$ Equal contributors

'Key laboratory of Plant Resources and Beijing Key Laboratory of Grape Science and Enology, Institute of Botany, Chinese Academy of Sciences, Beijing 100093, P. R., China

Full list of author information is available at the end of the article
}

and by about $2-5^{\circ} \mathrm{C}$ by the late twenty-first centry (http://www.ipcc.ch), and direct grape yield losses in the range of $2.5-16 \%$ for every $1^{\circ} \mathrm{C}$ increase in seasonal temperatures have been observed [2]. Therefore, a better understanding of the mechanisms involved in thermotolerance would be greatly significant and would lay the theoretical foundation for formulating the strategies of adaptation to high temperatures.

Direct injuries associated with high temperatures include protein denaturation, aggregation, and increased fluidity of membrane lipids. Indirect or slower heat injuries include inactivation of enzymes in chloroplasts and mitochondria, inhibition of protein synthesis, protein 
degradation and loss of membrane integrity $[3,4]$. Photosynthesis is a very sensitive process to heat stress. The inhibition of photosystem (PS) II leads to a change in variable chlorophyll a fluorescence, and in vivo chlorophyll may be used to detect changes in the photosynthetic apparatus, for example, with an O-J-I-P test $[5,6]$. Heat stress also affects the organization of microtubules by splitting and/or elongating the spindles, forming microtubule asters in mitotic cells, and elongating the phragmoplast microtubules [7]. These injuries eventually lead to starvation, inhibition of growth, reduced ion flux, and the production of toxic compounds and reactive oxygen species (ROS) [3,8]. To counter the effects of heat stress on cellular metabolism, plants and other organisms respond to temperature changes by reprogramming their transcriptome, proteome, metabolome and lipidome; that is, by altering their composition of certain transcripts, proteins, metabolites and lipids. Such changes are aimed at establishing a new steady-state balance of metabolic processes that can enable the organism to function, survive and even reproduce at a higher temperature [4]. In general, most of the previous studies about heat stress focused on physiological or transcriptomic approaches. As protein metabolic processes, including synthesis and degradation, are most sensitive to heat stress, proteomics research on heat stress could have a large impact on the understanding of its consequences.

Proteomics became popular in the 1990s and has greatly evolved to a mature stage today. The most frequently used proteomic technique is the two-dimensional (D) gel technique, where differentially expressed spots are excised and analyzed by mass spectrometry (MS). Proteomic responses to heat stress have been widely studied in many species, including rice $[9,10]$, wheat $[11,12]$, barley [13], Populus euphratica [14], Norway spruce [15], bitter gourd [16]. However, not all types of proteins are amenable to gel-based electrophoresis and the dynamic range is somewhat limited [17]. Additionally, the co-migration and partial co-migration of proteins can compromise the accuracy of the quantification, and interfere with protein identification $[17,18]$. In recent years, a new technique termed iTRAQ (isobaric tags for relative and absolute quantitation) has been applied for proteomic quantitation. iTRAQ labeling overcomes some of the limitations of 2Dgel-based techniques, and also improves the throughput of proteomic studies. This technique has a high degree of sensitivity, and the amine specific isobaric reagents of iTRAQ allow the identification and quantitation of up to eight different samples simultaneously $[17,19,20]$.

Grapevines are widely cultivated fruit vines around the world, and are mainly used for juice, liquor and wine production [21]. Heat stress is known to retard the growth and development of grapes, resulting in the decline of the yield and quality of the berry [22]. Similar to other plants, the previous studies on the response of grapevines to high temperatures have mainly focused on physiological changes including photosynthesis, respiration, cell membrane stability, hormone changes and antioxidant systems [22-29]. However, the underlying mechanisms of heat stress are still unclear. Transcriptomic analysis of grape (Vitis vinifera L.) leaves was conducted using the Affymetrix Grape Genome oligonucleotide microarray $(15,700$ transcripts $)$ under heat stress and subsequently recovery [29]. The effect of heat stress and recovery on grape appears to be associated with multiple processes and mechanisms including stressrelated genes, transcription factors, and metabolism [29]. However, the transcription patterns are not always directly concomitant with protein expression levels [30], and there are currently no reports on proteomic analyses in grapevines under heat stress. There have been, however, several reports of proteomic analyses of grapes (fruit). In order to understand the berry development and ripening process, Marti'nez-Esteso et al. (2011) correlated the proteomic profiles with the biochemical and physiological change occurring in grapes. They identified and quantified 156 and 61 differentially expressed proteins in green and ripening phases, respectively, through a top-down proteomic approach based on difference gel electrophoresis (DIGE) followed by tandem mass spectrometry (MS/MS) [31]. Basha et al. used the 2D-PAGE to identify unique xylem sap proteins in Vitis species with Pierce's disease (PD), a destructive bacterial disease of grapes caused by Xylella fastidiosa [32]. Martinez-Esteso et al. (2011) also identified 695 unique proteins in developing berries using the iTRAQ labeling technique, with quantification of 531 proteins [33]. Therefore, although there are many reports on the proteome of grapes, most have focused on fruit development [31,33-35] and fruit disease [36-40]. To the best of our knowledge, there are only a few grape proteomic studies which have addressed grapevine responses to abiotic stresses, including water or salt stress [41-43]. None of these studies have yet addressed heat stress of grape leaves. Moreover, although the responses of some plants to stress are generally well-studied, relatively few studies have focused on the mechanisms associated with recovery after stress [44-47]. This recovery process from heat stress in plants is very important to survival, and the degree of recovery from stress is a direct index of plant thermotolerance [44]. As, there are potentially differences between the recovery and the direct heat response mechanisms in plants [48], a proteomic evaluation and comparison of these processes is warranted.

In this study, we used the iTRAQ labeling technique to assess proteome changes in 'Cabernet sauvignon' leaves of $V$. vinifera under heat stress and their subsequent recovery, in order to better understand the thermotolerance mechanism in grapevines. 


\section{Results}

Thermostability of cell membranes in grapevine leaves under heat stress and subsequent recovery

The present study investigated changes in the cell membrane thermostability of 'Cabernet Sauvignon' grapevine leaves under heat stress and subsequent recovery. We used the thiobarbituric acid reactive substances (TBARS) concentrations as an indicator of the peroxidation and destruction of lipids with subsequent membrane damage [9]. One-way ANOVA analysis showed that heat treatment $\left(43^{\circ} \mathrm{C}\right.$ for $\left.6 \mathrm{~h}\right)$ significantly increased the TBARS concentrations in grape leaves (Figure 1), indicating the occurrence of damage to the cell membrane in the grapevine leaves under the heat treatment. After subsequent recovery, there was no difference in TBARS concentrations between heat-treated and control leaves (Figure 1).

\section{Changes in the electron transport chain of PSII under heat stress and subsequent recovery}

The O-J-I-P test was used to investigate changes in the electron transport chain of PSII. It has been shown that heat stress can induce a rapid rise in the O-J-I-P test. This phase, occurring at around $300 \mu$ s and labeled as $\mathrm{K}$, is caused by an inhibition of the oxygen evolution complex (OEC). The amplitude of step $\mathrm{K}\left(\mathrm{W}_{\mathrm{k}}\right)$ can therefore be used as a specific indicator of damage to the PSII donor site [49]. In addition, $\mathrm{RC}_{\mathrm{QA}}$ indicates the density of the active section of $\mathrm{Q}_{\mathrm{A}}$-reducing PSII reaction centers. In the present study, compared with the control (un-stressed conditions), heat stress resulted in an elevated $\mathrm{W}_{\mathrm{K}}$ and a lowered $\mathrm{RC}_{\mathrm{QA}}$ value (Figure $2 \mathrm{~A}, \mathrm{~B}$ ). After recovery, $\mathrm{W}_{\mathrm{K}}$ declined and $\mathrm{RC}_{\mathrm{QA}}$ ascended to the control levels.

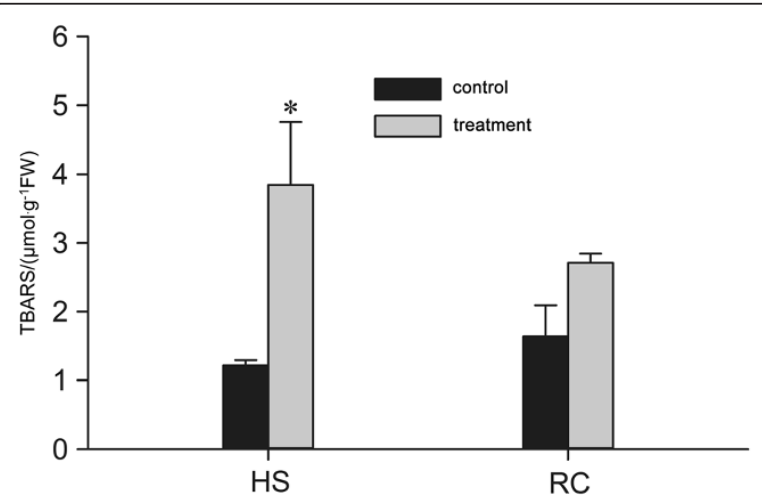

Figure 1 TBARS in grape leaves under heat stress and subsequent recovery. It is showed that heat treatment $\left(43^{\circ} \mathrm{C}\right.$ for $\left.6 \mathrm{~h}\right)$ significantly increased the TBARS concentrations in grape leaves and after subsequent recovery, there was no difference in TBARS concentrations between heat-treated and control leaves. Each value represents the mean \pm standard error of the mean (S.E.M.) of three replicates. The asterisks indicate the significance of differences between treatments and their corresponding controls (* $P<0.05$ ).
Figure $2 \mathrm{C}, \mathrm{D}, \mathrm{E}$ demonstrates the changes in maximum quantum yield for primary photochemistry $\left(\varphi_{\mathrm{Po}}\right)$, the quantum yield for electron transport $\left(\varphi_{\text {Eo }}\right)$, the probability that a trapped excitation moves an electron into the electron transport chain beyond $\mathrm{Q}_{\mathrm{A}}^{-}\left(\psi_{\mathrm{Eo}}\right)$ in grape leaves during high temperature stress and recovery, respectively. $\varphi_{\text {Po }}, \varphi_{\text {Eo }}, \psi_{\text {Eo }}$ decreased in grape leaves under heat stress, and went back to the control levels after recovery. $\delta_{\text {Ro }}$ signifies the redox state of photosystem I (PSI), i.e., the efficiency with which an electron transfers from plastoquinone (PQ) through PS I to reduce the PS I end electron acceptors. The $\delta_{\text {Ro }}$ value at $43^{\circ} \mathrm{C}$ rose significantly. However, these parameters returned to control levels after recovery (Figure 2C-F).

\section{Protein response to heat stress and/or recovery in grape leaves revealed by iTRAQ analysis}

Two hundred and seventy-four proteins were quantified with at least one significant peptide sequence and 174 of these characterized proteins were differentially expressed, i.e. an expression ratio $>1.50$ or $<0.67$ [50-53] under heat stress or recovery compared to their corresponding controls. Heat stress and recovery affected protein expression levels in various ways. During heat stress, 48 proteins were upregulated, and 65 were downregulated, while 41 were upregulated and 62 were downregulated after recovery, compared to their corresponding control levels. There were 71 (23 up- and 48 downregulated) proteins and 53 (19 up- and 34 downregulated) proteins responding to only heat stress or recovery, respectively, while 42 proteins were differentially expressed in both heat stress and recovery. Among these 42 proteins, eight proteins were upregulated both under heat stress and recovery, while nine proteins showed an opposing trend under the two conditions. Seventeen proteins were upregulated under heat stress and downregulated during recovery, while eight proteins were downregulated under heat stress but upregulated during recovery. In addition, six upregulated proteins and two downregulated proteins were only identified under recovery from heat stress (Figure 3).

\section{Functional classification, subcellular localization and enrichment analysis of differentially expressed proteins under heat stress and subsequent recovery}

Among the 174 differentially expressed proteins, 127 were characterized as hypothetical or unknown proteins under the grape genomics information category in uniprot (http://www.uniprot.org/). To gain functional information about these proteins, BLASTP (http://www.ncbi. nlm.nih.gov/BLAST/) was used to search for homologous proteins against the NCBI non redundant $(\mathrm{Nr})$ protein database. BLAST searching was able to align 117 of the unknown proteins (Additional file 1). Among these 


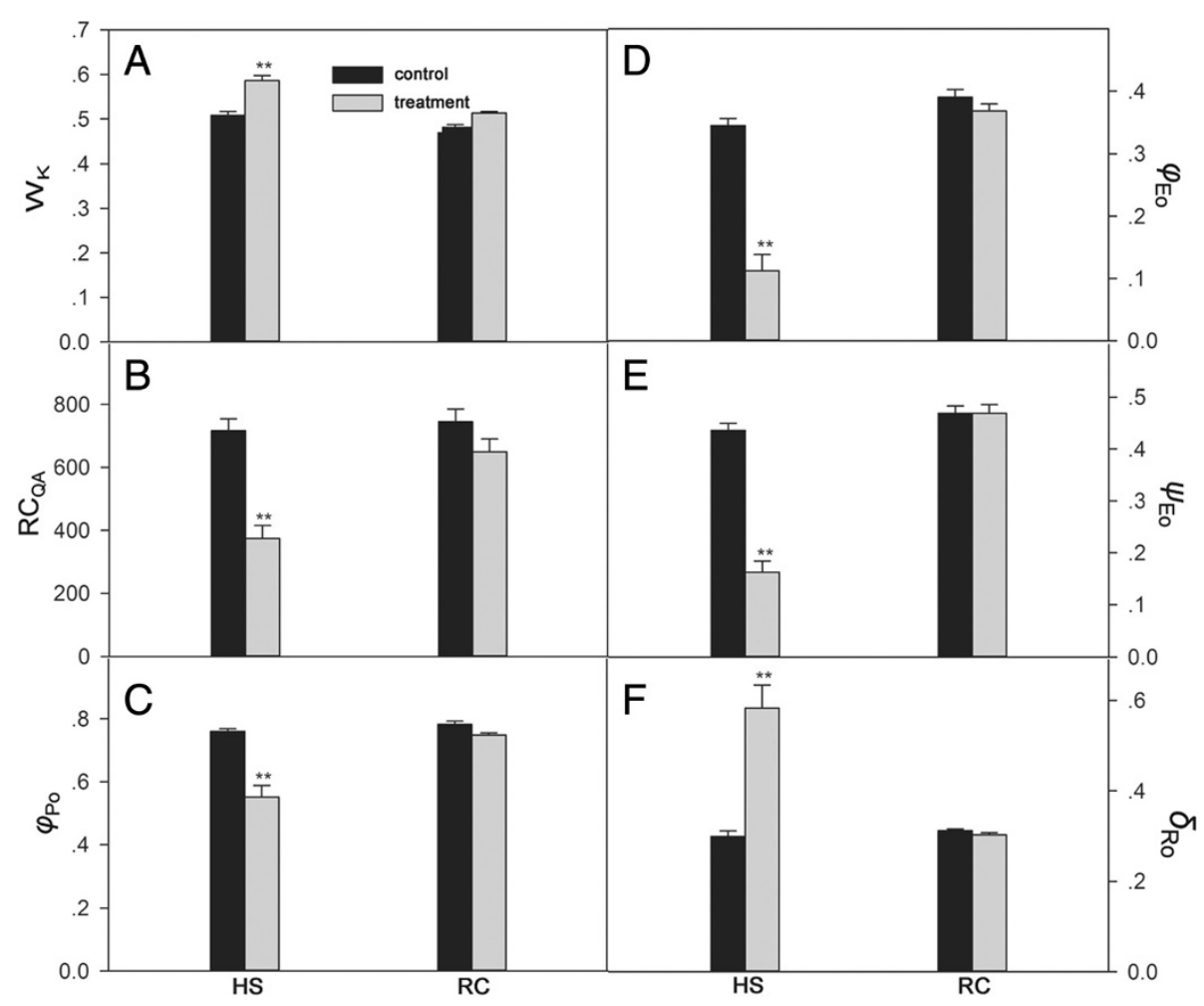

Figure 2 Donor side $\left(\mathrm{W}_{\mathrm{k}}\right)$, reaction center $\left(\mathrm{RC}_{\mathrm{QA}}\right)$, acceptor side $\left(\varphi_{\mathrm{Po}}, \psi_{\mathrm{Eo}}, \varphi_{\mathrm{Eo}}\right)$ parameters of PSII and $\delta_{\mathrm{Ro}}$ (the efficiency with an electron can move from plastoquinone (PQ) through PSI to the PSI end electron acceptor) in grape leaves under heat stress and subsequent recovery. Each value represents the mean \pm S.E. of five replicates. The asterisks indicate the significance of differences from their corresponding control (* $P<0.05$, ** $P<0.01)$. The detailed meanings of $W_{\mathrm{k}}, \mathrm{RC} C_{\mathrm{QA}}, \varphi_{\mathrm{PO}}, \psi_{\text {EO }}, \varphi_{\mathrm{EO}}$ and $\delta_{\mathrm{Ro}}$ were shown in Additional file 7.

aligned proteins, $90.6 \%$ had an E-value of less than 1.0E50 and showed very strong homology while the remaining 9.4\% had an E-value of between 1.0E-10 and 1.0E-50. The identities distribution defined $27.4 \%$ of these aligned proteins as having a matched identity greater than $90 \%, 71.8 \%$ between $60 \%$ and $90 \%$ and only one protein $(59.93 \%)$ lower than $60 \%$. These results indicating that the unknown proteins might have similar function with the aligned proteins respectively. These

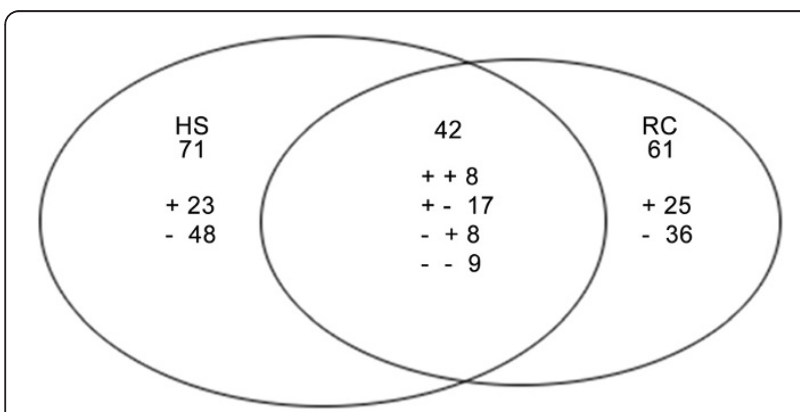

Figure 3 Venn diagram of differentially expressed proteins that were up- or downregulated by heat stress or recovery. The " +" and "- "indicate up- and downregulated proteins, respectively. differentially expressed proteins were classified into 26 functional categories according to MapMan ontology as shown in Figure 4 and Additional file 2. The main categories included photosynthesis, proteins and stress. In addition, enrichment analysis against agriGO (http:// bioinfo.cau.edu.cn/agriGO/) showed that differentially expressed proteins were mainly enrich in response to abiotic stimulus (GO: 0009628), generation of precursor metabolites and energy (GO: 0006091) and photosynthesis (GO: 0015979) of biological process. Moreover, subcellular localization of the 174 characterized proteins showed that 60 proteins (34\%) were located in chloroplast, five proteins (3\%) were assigned to the mitochondria, 14 proteins $(8 \%)$ belonged to secretory pathway, and 21 proteins $(12 \%)$ were classified as belonging to other locations. Unfortunately, 74 of the differentially-expressed proteins had unknown locations (Figure 5). These results indicated that quite a lot of chloroplast proteins are related to thermotolerance of grapevine.

\section{Comparative analysis of common responsive proteins} between heat stress and subsequent recovery There were 17 proteins that were upregulated by heat stress, but were then downregulated after recovery 


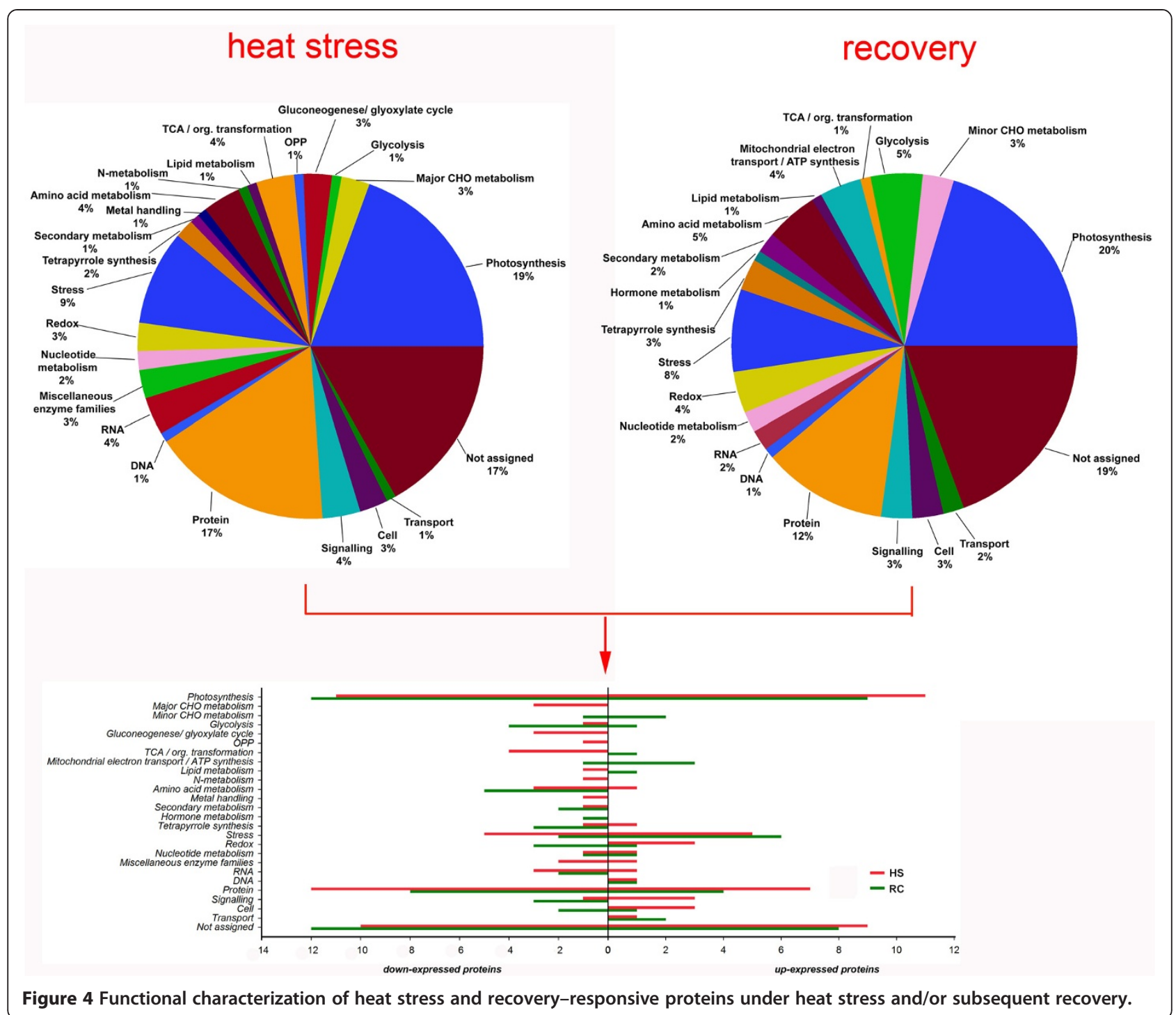

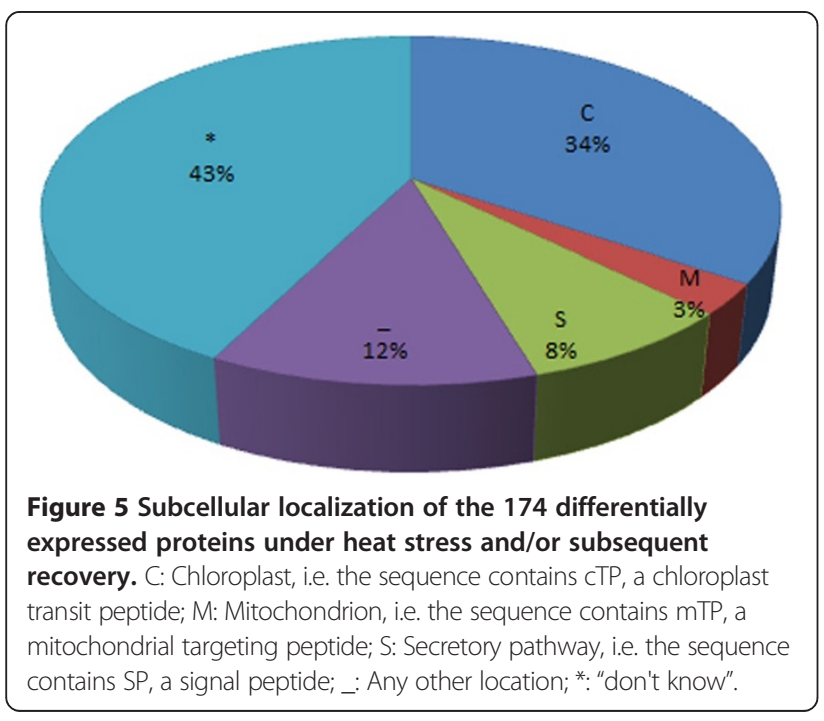

(Additional file 3). Three of these proteins were categorized as being related to photosynthesis, including PSI reaction center subunit $\mathrm{N}$ (PsaN), ATP synthase subunit beta (fragment), and Rubisco large chain. Interestingly, PsaN was upregulated 28 fold by heat stress but then downregulated more than 5 fold after recovery, compared with their corresponding controls. In addition, two of the proteins were related to metabolism: one is acetoacetyl-CoA thiolase, which condenses two molecules of acetyl-CoA to give acetoacetyl-CoA, and this is the first enzymatic step in the biosynthesis of isoprenoids via mevalonate, the other is coproporphyrinogen-III oxidase (CPOX), a key enzyme in the biosynthetic pathway of chlorophyll. Universal stress protein (USP), a transcription factor in abiotic stress, and thylakoidal ascorbate peroxidase (APX), involved in $\mathrm{H}_{2} \mathrm{O}_{2}$ detoxification, were also induced by heat stress and decreased after 
subsequent recovery. Moreover, proteins related to protein metabolism included one chloroplastic large subunit ribosomal protein (L12-1) and one translation initiation factor (eIF3f). Peptidyl-prolyl cis-trans isomerase and two transporters, the nascent polypeptide associated complex alpha and the mitochondrial import inner membrane translocase subunit Tim9 were also affected. One14-33-like protein, associated with a DNA binding complex that binds to the G-box was also identified.

Only eight proteins were upregulated by both heat stress and subsequent recovery (Additional file 3). One PSII subunit R (PsbR), one PSI subunit $\mathrm{H}$ (PsaH) and a Rubisco small submit were induced after heat stress and recovery. Additionally, two ribosomal proteins (S21e, S9) were also identified. Moreover, heat shock protein (HSP) 26 in chloroplast was induced 3.4 and 2.0 fold respectively by heat stress and recovery. Nucleoside diphosphate kinase 1 (NDPK1), involved in purine metabolism, was also induced more than 10 fold under heat stress, and returned to almost the control level after recovery.

Eight proteins were downregulated by heat stress but upregulated after subsequent recovery (Additional file 3). Among the eight proteins, two of them are related to photosynthesis, PSI subunit 1 (PsaA), PSII protein D1 (PsbA). Biotin carboxylase subunit, a component of the acetyl coenzyme A complex was downregulated 0.46 fold by heat stress but upregulated 1.6 fold after subsequent recovery. In addition, two stress-related proteins of the HSP90 family (HSP90-5, HSP90-7) were also identified. The three remaining proteins in this group were not assigned.

Additional file 3 shows nine proteins that were downregulated both by heat stress and subsequent recovery. Light-harvesting chlorophyll-protein complex II subunit B1 (LHCB1.4) in photosynthesis and a magnesiumchelatase $(\mathrm{MgCh})$ subunit ChlI-2 involved in chlorophyll biosynthesis were identified in this group. Cyanate hydratase which catalyzes the bicarbonate-dependent breakdown of cyanate to ammonia and bicarbonate in cyanogenic glycosides was also repressed both by heat stress and recovery. In addition, small subunit ribosomal protein SA and protein phosphatase $2 \mathrm{C}$ in protein metabolism was also repressed after heat stress and recovery.

\section{Analysis of proteins only responsive to heat stress}

A total of 71 proteins showed a specific response to heat stress, with 23 upregulated proteins, and 48 downregulated proteins (Additional file 4). Five of the 23 upregulated proteins are related to photosynthesis, including PsaF, three ATP synthase subunits $(\gamma, \delta, b)$ involved in the photosystem electron-transfer reaction, and a fructose bisphosphate aldolase (FBA) involved in the Calvin cycle. Of note, the ATP synthase CF (0) b subunit was upregulated 8.4 fold by heat stress. Ribosomal protein S1 involved in protein synthesis was also upregulated by heat stress. HSP22, located in the endoplasmic reticulum, and HSP21, located in the chloroplast, were induced 3.0 and 5.5 fold, respectively, under heat stress. Cytoplasmic $[\mathrm{Cu}-\mathrm{Zn}]$ superoxide dismutase (SOD), involved in redox, was also induced 5.0 fold under heat stress. In addition, 14-3-3-like protein was upregulated 1.8 fold by heat stress. Among the 48 downregulated proteins (Additional file 4), eight of them were involved in photosynthesis, including LHCB1.3, PsbP, and PsaL. Many other proteins were involved in a variety of metabolic mechanisms, including glucose-1-phosphate adenylyltransferase, two malate dehydrogenase enzymes $(\mathrm{MDH})$, nitrite reductase 1 in $\mathrm{N}$-metabolism and uracil phosphoribosyltransferase involved in nucleotide metabolism. There are also some carbohydrate metabolism-related proteins, such as UDPglucose pyrophosphorylase, which catalyze the reversible reaction between glycose-1-phosphate and UDP-glycose, dihydrolipoyl dehydrogenase in the tricarboxylic acid cycle (TCA) and 6-phosphogluconate dehydrogenase in the oxidative pentose phosphate pathway (OPP). Three proteins were identified as being stress-related; including osmotin-like protein and HSP70. Two identified proteins, Beta-1-3 glucanase and alcohol dehydrogenase, were annotated to miscellaneous enzyme families. In addition, ten proteins were involved in protein metabolism, including mitochondrial-processing peptidase subunit $\alpha$ and $\beta$, in protein targeting; methionine sulfoxide reductase $A$, in posttranslational modification; protease Do-like 8, and proteasome subunit $\alpha$ type- 5 in protein degradation and a $20 \mathrm{kDa}$ chaperonin, involved in protein folding. There are also five proteins are not assigned.

\section{Analysis of proteins only responsive to recovery from heat stress}

There were 25 proteins which were only upregulated after recovery from heat stress (Additional file 5). Four of these proteins are photosynthesis-related, including LHCB2.1, PsbS, PetB. Two upregulated stress proteins corresponded to the HSP70 family (HSP70-5, HSP70-11). HSP70-5 is located in the cytoplasm, while HSP70-11 is located in the endoplasmic reticulum and plays a role in facilitating the assembly of multimeric protein complexes inside the endoplasmic reticulum. Ribosomal proteins, including L22, EF-Ts, were also upregulated only upon recovery to heat stress.

Thirty-six proteins were downregulated only after recovery to heat stress (Additional file 5). Eight downregulated proteins were involved in photosynthesis, including PsbE, PsaD, PetC, PetD, FNR in light reaction and phosphoribulokinase, FBA, fructose-1,6- bisphosphatase in Calvin cycle. Two isoforms of FBA, glyceraldehyde-3phosphate dehydrogenase and phosphoglycerate kinase involved in glycolysis were also repressed after recovery 
from heat stress. Down-expressed proteins involved in amino acid metabolism included aspartate aminotransferase, serine-pyruvate aminotransferase, ketol-acid reductoisomerase, and aminomethyltransferase. Catalase (CAT) and APX involved in $\mathrm{H}_{2} \mathrm{O}_{2}$ detoxification were also downregulated after recovery from heat stress. Several proteins from this group were unfortunately unidentified.

\section{Discussion}

One of the many locations for heat stress injury in cells is the membrane. TBARS is the product of lipid peroxidation in plants. The chlorophyll $a$ fluorescence transient analysis (O-J-I-P test) is a powerful tool to probe the PSII reactions, which may help determine the state of the electron transport chain [54]. In this study, we investigated the TBARS content and chlorophyll fluorescence parameters in grape leaves under heat stress and subsequent recovery (Figures 1 and 2). These results showed that young grapevines of the 'Cabernet Sauvignon' varietal were damaged under heat stress at $43^{\circ} \mathrm{C}$ for $6 \mathrm{~h}$, but they subsequently recovered at $25^{\circ} \mathrm{C}$ for $18 \mathrm{~h}$. Differential proteomic analysis of grapevines under these two conditions were also performed, and the findings are further discussed below.

\section{Electron transport chain and related proteins involved in the photosynthesis}

Photosynthesis is known to be one of the most heat sensitive processes due to its complex mechanisms and requirement for enzymes. It is directly related to plant productivity and energy utilization. In this study we identified 34 dysregulated proteins involved in photosynthesis, upon heat stress and subsequent recovery. These accounted for one fifth of all differentially expressed proteins in this study (Table 1 and Figure 6). Moreover, enrichment analysis showed that photosynthesis was enriched under heat stress and/or recovery (Additional file 6 and Additional file 7).

PSII is thermally labile and is considered to be the most sensitive component of the electron transport chain $[55,56]$. The peripheral antennas of PSII are composed of major trimeric and minor monomeric LHCII proteins. In this study, the expression of LHCII1.3 and LHCII1.4 was inhibited under heat stress and increased after recovery, which indicated that LHCII1.3 and LHCII1.4, might be thermally labile. LHCB2.1 showed the same expression as control under heat stress while increased about 2.7 fold after recovery, suggesting that LHCB2.1 may be thermostable and solely involved in the recovery from heat stress. The OEC activity is in close association with the $33 \mathrm{kDa}$ (PsbO) and $23 \mathrm{kDa}$ (PsbP). $\mathrm{PsbO}$ is a key structural component of many different types of OECs and functions to stabilize the manganese cluster and modulate the $\mathrm{Ca}^{2+}$ and $\mathrm{Cl}^{-}$requirements for oxygen evolution [57]. Additionally, the 10-kDa PsbR protein has also been found play a role in stable association of the PsbP with the PSII core for water oxidation $[57,58]$. In the present study, PsbO-2 levels were not altered upon heat stress or subsequent recovery, the PsbP precursor was repressed under heat stress but returned to control level after subsequent recovery, while PsbR was elevated approximately eight fold with respect to its control under heat stress, and remained upregulated two fold upon subsequent recovery. In addition, the chlorophyll fluorescence parameter $\mathrm{W}_{\mathrm{k}}$ showed that the OEC of PSII was damaged under heat stress, but returned back to the normal physiological level in the recovery phase (Figure 2). Therefore, these combined results suggest that PsbR may play an important role in maintaining the stability of the OEC of PSII compared to PsbO and PsbP in grape leaves.

In the present study, $\mathrm{RC}_{\mathrm{QA}}$ values decreased under heat stress and increased to the control level after subsequent recovery (Figure 2), indicating that the PSII reaction center was inhibited by heat stress and then recovered when the stress was removed. The change of D1 protein corroborated this result (Table 1). The multisubunits (PetA, PetB, PetC and PetD) complex of Cyt $b_{6} / f$ is a crucial component for the acceptor side of electron transport chain of PSII [59]. In the present study, three subunits PetB, PetD and PetC were differentially expressed. The expression level of PetB, PetC and PetD did not change significantly under heat stress, however, after recovery, the expression of PetC and PetD was largely inhibited while PetB was induced. In addition, $\varphi_{\text {Eo }}$ and $\psi_{\text {Eo }}$ were reduced in grape leaves under heat stress, then returned to control levels with the subsequent recovery (Figure 2). This suggests that the function of the acceptor portion of the electron transport chain of PSII including $\mathrm{Cyt} b_{6} / f$ complex recovered from heat stress. These combined results suggest that PetB may promote the Cyt $b_{6} / f$ complex to recover from heat stress.

The study showed that many proteins in the PSI complex changed upon heat stress (Table 1). PSI consists of a core complex and a peripheral antenna. In plants, these two functional units result from the assembly of at least 19 protein subunits. The PSI core complex contains 15 subunits, including PsaA to PsaL and PsaN to PsaP which play important roles in PSI function. For example, PsaF is located in the thylakoid lumen, and contains a lysine-rich helix-loop-helix motif that has been demonstrated to interact with plastocyanin in plants and with plastocyanin (PC) or Cytochrome $c_{6}$ in algae [60]. PsaN is necessary for the docking PC to the PSI complex, and is the only subunit located entirely on the lumenal side of PSI. In the present study, it was shown from the chlorophyll $a$ fluorescence parameter $\delta_{\text {Ro }}$ that PSI was damaged under heat stress and recovered to the control 
Table 1 Proteins involved in photosynthesis under heat stress and/or subsequent recovery

\begin{tabular}{|c|c|c|c|c|c|}
\hline \multirow{2}{*}{$\begin{array}{l}\text { Protein } \\
\text { accession }\end{array}$} & \multicolumn{2}{|c|}{ Fold change } & \multirow[t]{2}{*}{ Bin } & \multirow[t]{2}{*}{ Species } & \multirow[t]{2}{*}{ Description } \\
\hline & HS & RC & & & \\
\hline A5ASG6 & 0.924 & 2.708 & 1.1.1.1 & Arabidopsis thaliana & Photosystem II light harvesting complex protein 2.1, LHCB2.1 \\
\hline A5BPB2 & 0.438 & 0.524 & 1.1.1.1 & Arabidopsis thaliana & Putative light-harvesting chlorophyll-protein complex II subunit B1, LHCB1.4 \\
\hline A5B514 & 0.456 & 1.084 & 1.1.1.2 & Arabidopsis thaliana & Chlorophyll a/b-binding protein 1, chloroplastic, LHCB1.3 \\
\hline D7UA58 & 0.59 & 1.176 & 1.1.1.2 & Gossypium hirsutum & PsbP precursor \\
\hline Q67H94 & 1.045 & 0.608 & 1.1.1.2 & Muscari comosum & Cytochrome $b_{559}$ subunit alpha (Fragment), PsbE (cytb559a) \\
\hline E0CR63 & 1.041 & 1.603 & 1.1.1.2 & Ricinus communis & Photosystem II 22 kDa protein, PsbS, chloroplast precursor \\
\hline B6VJV1 & 0.601 & 1.928 & 1.1.1.2 & Vitis vinifera & Photosystem II protein D1, PsbA (D1) \\
\hline A5AWT3 & 7.737 & 2.387 & 1.1.1.2 & Nicotiana tabacum & Photosystem II 10 kDa polypeptide, PsbR, chloroplastic \\
\hline F6GY64 & $N A^{*}$ & 1.645 & 1.1.1.2 & Populus trichocarpa & One helix protein 2 \\
\hline A5AW35 & 0.656 & 1.226 & 1.1.2.2 & Ricinus communis & Photosystem I reaction center subunit XI, PsaL, chloroplastic \\
\hline A5B2H3 & 7.317 & 1.234 & 1.1.2.2 & Ricinus communis & Photosystem I reaction center subunit III, chloroplast precursor, PsaF \\
\hline A5AEB4 & 0.878 & 0.582 & 1.1.2.2 & Ricinus communis & Photosystem I reaction center subunit II, PsaD, chloroplast precursor \\
\hline Q0ZJ20 & 0.545 & 5.057 & 1.1.2.2 & Vitis vinifera & photosystem I P700 apoprotein A1, PsaA \\
\hline F6I0D9 & 28.065 & 0.185 & 1.1.2.2 & Medicago truncatula & Photosystem I reaction center subunit N, PsaN \\
\hline A5BHE6 & 5.11 & 2.172 & 1.1.2.2 & Ricinus communis & Photosystem I reaction center subunit VI, PsaH \\
\hline A5BX41 & 0.846 & 0.236 & 1.1.3 & Vitis vinifera & Cytochrome $b_{6} / f$ complex iron-sulfur subunit, PetC \\
\hline Q0ZIY8 & 1.479 & 0.417 & 1.1.3 & Vitis vinifera & Cytochrome $b_{6} / f$ complex subunit IV, PetD \\
\hline Q0ZIY9 & 0.8 & 1.881 & 1.1 .3 & Vitis vinifera & Cytochrome $b_{6}$, PetB \\
\hline Q67H40 & 0.392 & 0.818 & 1.1.4 & Muscari comosum & ATP synthase subunit beta, chloroplastic \\
\hline Q0ZJ34 & 8.386 & 0.957 & 1.1.4 & Vitis vinifera & ATP synthase CF (0) b subunit \\
\hline F6H7M1 & 1.502 & 1 & 1.1 .4 & Vitis vinifera & ATP synthase gamma chain, chloroplastic-like isoform 1 \\
\hline F6HVW3 & 1.995 & 1.03 & 1.1.4 & Nicotiana tabacum & ATP synthase delta chain, chloroplastic \\
\hline Q95FU2 & 1.83 & 0.401 & 1.1.4 & Coccoloba uvifera & ATP synthase beta subunit \\
\hline E0CQ75 & 1.234 & 0.554 & 1.1.5.3 & Ricinus communis & Ferredoxin-NADP reductase, FNR \\
\hline D7TQZ8 & 0.666 & 0.726 & 1.2 .2 & Glycine max & Peroxisomal (S)-2-hydroxy-acid oxidase GLO1-like \\
\hline А5ВТМ9 & 2.969 & 0.505 & 1.3.1 & Vitis vinifera & Ribulose-1,5-bisphosphate carboxylase/oxygenase large subunit, RbcL \\
\hline Q21314 & 1.627 & 1.886 & 1.3 .2 & Vitis pseudoreticulata & ribulose-1,5-bisphophate carboxylase/oxygenase small subunit \\
\hline A5BHS5 & 0.61 & 1.167 & 1.3.4 & Glycine max & NADP-dependent glyceraldehyde-3-phosphate dehydrogenase-like \\
\hline F6HFL6 & 1.833 & 0.733 & 1.3.6 & Vitis vinifera & Fructose-bisphosphate aldolase, FBA \\
\hline F6GWQ0 & 0.799 & 0.626 & 1.3.6 & Vitis vinifera & Fructose-bisphosphate aldolase \\
\hline A5AYR7 & 1.476 & 0.664 & 1.3 .7 & Glycine max & Fructose-1,6-bisphosphatase, chloroplastic-like \\
\hline A5BE19 & 0.84 & 0.447 & 1.3 .12 & Vitis vinifera & Phosphoribulose kinase, putative \\
\hline D7THJ7 & 0.482 & 0.739 & 1.3.13 & Ricinus communis & Ribulose bisphosphate carboxylase/oxygenase activase 1, chloroplast precursor \\
\hline F6HBT1 & 0.594 & 1.004 & 1.3 .13 & Glycine max & Ribulose bisphosphate carboxylase/oxygenase activase, chloroplastic-like \\
\hline
\end{tabular}

*The proteins were not quantified under heat stress or subsequent recovery.

$\mathrm{HS}$ refers to the fold change in heat stressed proteins, with respect to controls, while RC refers to the fold change in proteins after recovery, with respect to controls.

level when returned to normal temperatures (Figure 2). Consistent with this observation, the levels of PsaA and PsaL declined under heat stress. However, the expression level of PsaA remained 5 fold higher compared to the control after subsequent recovery, suggesting that PsaA may have a positive effect in the recovery phase of PSI. In addition, the expression of PsaF, PsaH and PsaN increased by a 7.3, 5.1 and 28.1 fold respectively under heat stress, which indicated that PsaF, PsaH and PsaN might play a role of protection from heat stress in the PSI complex of grape leaves. It is especially interesting that while all proteins of the PSI complex inhibited under heat stress were hydrophobic, all proteins induced under heat stress were hydrophilic.

ATP synthase produces ATP from ADP in the presence of a proton gradient across the membrane. F-type 

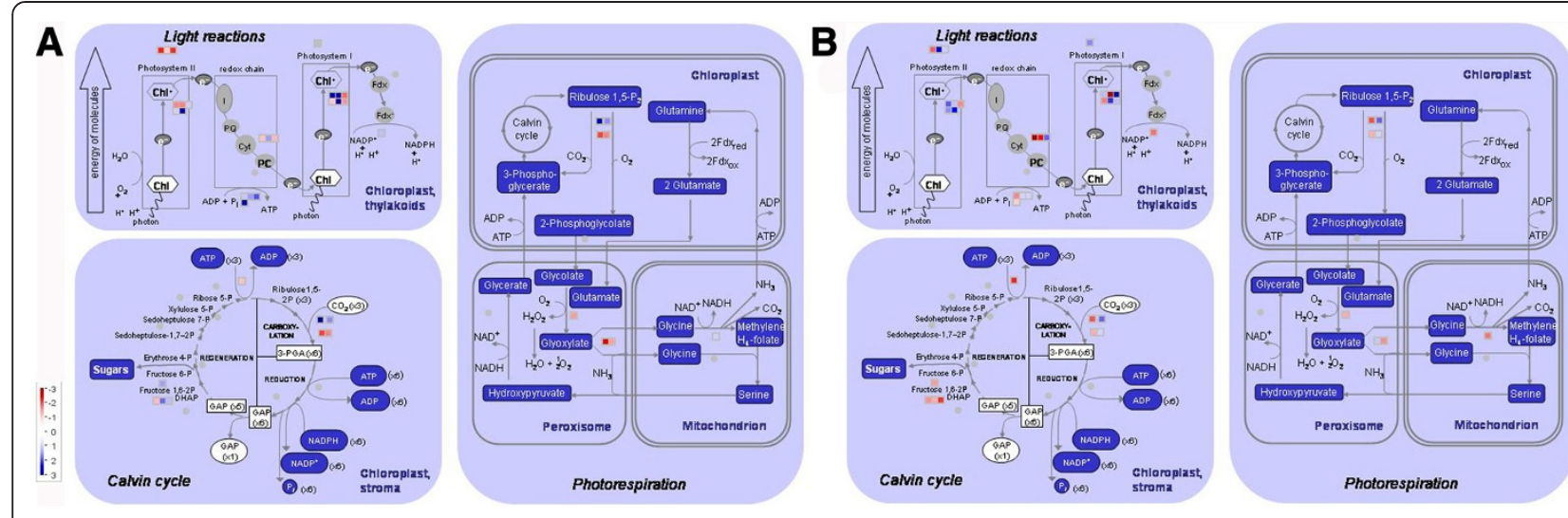

Figure 6 MapMan visualization of photosynthesis in grapevine leaves under heat stress (A) and subsequent recovery (B).

ATPase has two components, CF (1) - the catalytic core - and CF (0) - the membrane proton channel. CF (1) has five subunits: $\alpha, \beta, \gamma, \delta$ and $\varepsilon$ while CF (0) has four main subunits: $a, b, b^{\prime}$ and c. The $\alpha$ chain is the largest subunit of the ATP synthase. The $\gamma$ chain is believed to be important in regulating ATPase activity and the flow of protons through the CF (0) complex. In the study, all the identified ATP synthase subunits $(\gamma, \delta$ and $\mathrm{b}$ of CF (0)) were upregulated under heat stress, and all of them recovered to their control levels after subsequent recovery. Especially, the expression of subunit b is increased by 8.4 fold under heat stress. These result suggested that these three subunits may have a protective role against heat stress for ATP synthase, and continue to provide energy for maintaining the normal physiological processes of grapevines.

\section{Proteins involved in abiotic stress and redox regulation}

Nineteen identified dysregulated proteins were functionally characterized as being involved in stress response (Table 2). Most of them were assigned to one of the four major classes of molecular chaperones, HSP90, HSP70, HSP60 and sHSPs, however, no proteins belonged to HSP100 family. Plants respond to different abiotic stress by inducing the synthesis of proteins from the heat shock protein (HSP)/chaperone family which have been shown to play a crucial role in protecting plants against stress by re-establishing normal protein conformations and thus cellular homeostasis [61]. In this study, nine HSPs were differentially expressed under heat stress or after subsequent recovery. Proteins from the HSP90 family do not only manage protein folding [62,63], but also play a major role in signal-transduction networks, cell-cycle control, protein degradation and protein trafficking [64-66]. A previous study in P. euphratica showed that a putative HSP90 was upregulated early upon heat stress and later returned to control values [14]. In our study, three members of HSP90 family were identified and differentially expressed. Two of them were inhibited, while the expression of HSP90-1 was not affected by heat stress. However, all of them were upregulated during subsequent recovery. Proteins from the HSP70 family are essential for preventing aggregation and assisting re-folding of non-native proteins under both normal and stressing environmental conditions $[62,67]$. They are involved in protein import and translocation processes, and in facilitating the proteolytic degradation of unstable proteins by targeting these proteins to lysosomes or proteasomes [62]. Previous reports have documented that HSP70 were accumulated under heat stress $[9,68]$. In our research, three members of the HSP70 family were identified. One of the HSP70 family proteins was repressed under heat stress and recovered to the control level during the subsequent recovery (Table 2) while the other two had no difference compared to their control under heat stress but were downregulated during the recovery phase (Table 2). This suggests that the many isoforms of HSP70 play different roles under heat stress. In plants, the sHSPs are abundant and diverse, and can be classified into five families according to their cellular localization; including cytosol (class I and II), chloroplast (class III), endoplasmic reticulum (class IV), and mitochondrion (class V) [9,69-71]. In addition, sHSPs have been reported to be involved in protecting macromolecules like enzymes, lipids, nucleic acid, and mRNAs from dehydration [72]. In our study, one protein (HSP22) was predicted to be an endoplasmic reticulum-targeted sHSP, whereas the other sHSP (HSP21) was predicted to be chloroplast-targeted. A previous study in Arabidopsis showed the expression of HSP21 and HSP22 significantly increased under heat stress [73]. In our study, the similar results were observed, and moreover, the expression of HSP21 and HSP22 return to control levels after subsequent recovery. This also agrees with our previous findings, in which the mRNA level of HSP21 and HSP22 exhibited similar increases [29]. In addition, increased thermotolerance has 
Table 2 Proteins involved in abiotic stress and redox under heat stress and/or subsequent recovery

\begin{tabular}{|c|c|c|c|c|c|}
\hline \multirow{2}{*}{$\begin{array}{l}\text { Protein } \\
\text { accession }\end{array}$} & \multicolumn{2}{|c|}{ Fold change } & \multirow[t]{2}{*}{ Bin } & \multirow[t]{2}{*}{ Species } & \multirow[t]{2}{*}{ Description } \\
\hline & HS & RC & & & \\
\hline A5BS35 & 0.412 & 1.031 & 20.1 & Nicotiana tabacum & NtPRp27 \\
\hline A5C2C9 & 0.877 & 0.324 & 20.1 & Ricinus communis & Protein MLO, putative \\
\hline A5AHJ5 & 0.114 & 1.149 & 20.2 & Vitis vinifera & Osmotin-like protein \\
\hline F6HYG1 & 0.409 & 0.933 & 20.2 .1 & Ricinus communis & Heat shock $70 \mathrm{kDa}$ protein \\
\hline F6HJZ4 & 3.046 & 0.978 & 20.2 .1 & Corylus heterophylla & Heat shock protein 22, endoplasmic reticulum, HSP22 \\
\hline A5B868 & 5.531 & 1.45 & 20.2 .1 & Solanum lycopersicum & Heat shock protein 21, chloroplast, HSP21 \\
\hline F6HU55 & 0.878 & 1.989 & 20.2 .1 & Cucumis sativus & Heat shock protein 70 \\
\hline F6HYK6 & 1.005 & 2.591 & 20.2 .1 & Vitis vinifera & Similar to PsHSP71.2 \\
\hline A5ADL7 & 1.312 & 2.959 & 20.2 .1 & Arabidopsis thaliana & Heat shock protein 90.1, cytoplasmic, HSP90-1 \\
\hline A5BX00 & 0.382 & 1.782 & 20.2 .1 & Arabidopsis thaliana & HSP90-like protein 7, HSP90-7 \\
\hline F6HGF1 & 0.598 & 2.854 & 20.2 .1 & Ipomoea nil & Heat shock protein 90 \\
\hline E0CVB4 & 3.416 & 1.983 & 20.2 .1 & Nicotiana tabacum & Heat shock protein 26 \\
\hline F6HKZ7 & 5.463 & 0.748 & 20.2 .99 & Ricinus communis & ATOZI1 \\
\hline D5LN28 & 1.8 & 0.472 & 20.2 .99 & Vitis pseudoreticulata & Universal stress protein (USP) family protein \\
\hline EOCQM3 & 9.846 & 2.943 & 21.1 & Populus trichocarpa & Thioredoxin M \\
\hline D7SKR5 & 1.32 & 0.648 & 21.2 .1 & Vitis vinifera & Ascorbate peroxidase, APX \\
\hline F6H0K6 & 1.508 & 0.434 & 21.2 .1 & Glycine max & L-ascorbate peroxidase T, chloroplastic-like isoform 2 \\
\hline F6HTX9 & 4.904 & 0.99 & 21.6 & Vitis vinifera & Cytoplasmic [Cu-Zn] SOD \\
\hline D7UD99 & 1.071 & 0.604 & 21.6 & Vitis vinifera & Catalase, CAT \\
\hline
\end{tabular}

been previously achieved by overexpressing the plastidial Hsp21 in tomato [74]. Therefore, these sHSPs may have the important functions in alleviating heat stress in grapevines.

The antioxidant enzymes are known to play important roles in scavenging or reducing excessive reactive oxygen species (ROS) which are produced under stress conditions, in order to maintain cell redox homeostasis [9]. In this study, we identified a group of antioxidant enzymes including $[\mathrm{Cu}-\mathrm{Zn}] \mathrm{SOD}, \mathrm{CAT}, \mathrm{APX}$ and thioredoxin. $[\mathrm{Cu}-\mathrm{Zn}] \mathrm{SOD}$ which plays a central role in protecting against oxidative stress is generally found in the cytosol and chloroplasts (Table 2). The cytoplasmic [Cu- $\mathrm{Zn}$ ] SOD showed considerable upregulation (approximately 5 fold) under heat stress, followed by a return to the control level after subsequent recovery. This is in agreement with published results in the heat-tolerant Agrostis scabra, while these redox proteins were not detected in the heat-sensitive Agrostis stolonifera [75]. In addition, the expression of APX increased under heat stress in our study. Thioredoxins are small proteins catalyzing thiol-disulfide interchange, which is involved in the regulation of the redox environment in cells $[76,77]$. The most prominent candidates of proteins are thioredoxin $h$ in Populus euphratica Oliv. and rice leaves, upon heat stress $[9,14]$. Thioredoxin M4 was predicted to be located in chloroplast in our study, and was upregulated almost 10 fold under heat stress and maintained approximately 3 fold after subsequent recovery (Table 2). These results suggest that cytosolic [Cu-Zn] SOD, APX and chloroplastic thioredoxin have important roles in maintaining redox homeostasis in grapevine cells under heat stress (Figure 7).

\section{Proteins involved in metabolism}

The expression of most proteins predicated to be involved in metabolism was slightly downregulated in grape leaves under heat stress (Table 3), indicating that the metabolism of 'Cabernet Sauvignon' grapevine was mildly affected under heat stress. In the present study, three proteins identified were involved in nucleotide metabolism. Most significantly, NDPK1, which plays a major role in the synthesis of nucleoside triphosphates other than ATP was upregulated more than 10 fold under heat stress, and declined to 1.7 fold following recovery, compared to controls. Fukamatsu et al. showed that Arabidopsis NDPK1 is a component of ROS signaling pathways by interacting with three CATs [78]. Furthermore, in Neurospora crassa, NDPK1 is suggested to control CATs in response to heat, oxidative stress and light, and results have indicated that NDPK1 protein was translocated from the plasma membrane to the cytoplasm in response to light, and may interact with CAT [79]. Together with our findings, we suggest that 


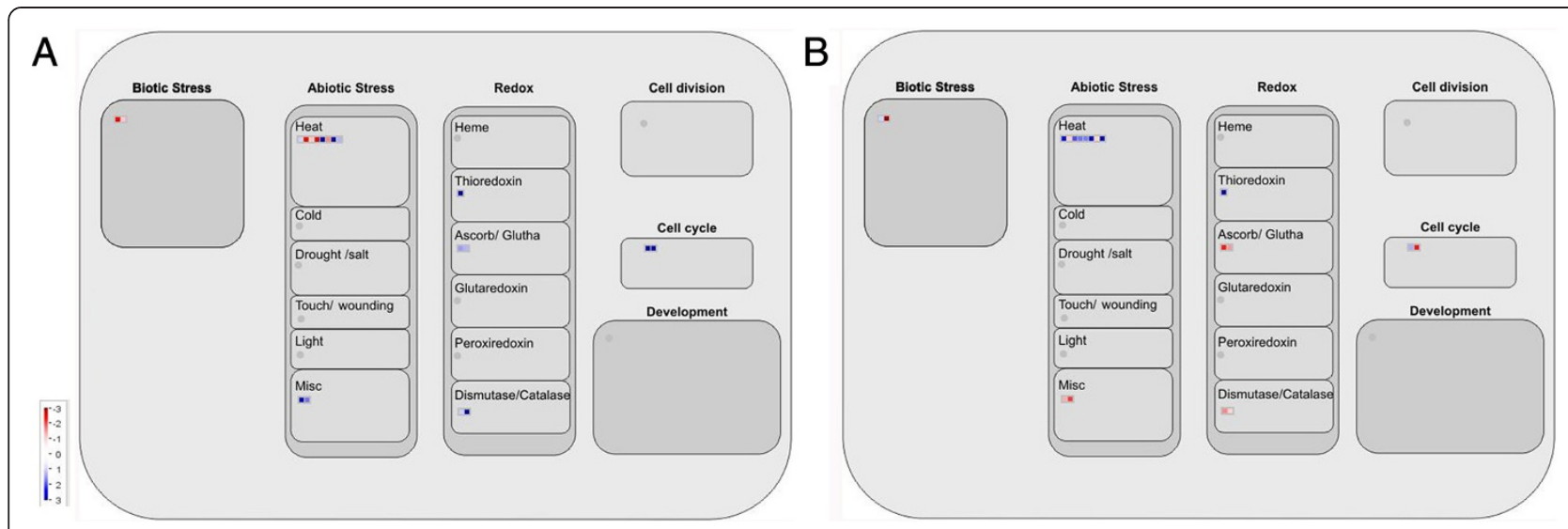

Figure 7 Overview of cellular response in grapevine leaves under heat stress (A) and subsequent recovery (B) visualized by MapMan.

Table 3 Proteins involved in metabolism under heat stress and/or subsequent recovery

\begin{tabular}{|c|c|c|c|c|c|}
\hline \multirow{2}{*}{$\begin{array}{l}\text { Protein } \\
\text { accession }\end{array}$} & \multicolumn{2}{|c|}{ Fold change } & \multirow[t]{2}{*}{ Bin } & \multirow[t]{2}{*}{ Species } & \multirow[t]{2}{*}{ Description } \\
\hline & HS & RC & & & \\
\hline D7TDB6 & 0.547 & 1.053 & 2.1.2.1 & Vitis vinifera & ADP-glucose pyrophosphorylase catalytic subunit \\
\hline F6HDM4 & 0.516 & 1.178 & 2.1.2.1 & Vitis vinifera & Glucose-1-phosphate adenylyltransferase \\
\hline Q9S944 & 0.169 & 0.882 & 2.2.1.3.3 & Vitis vinifera & Vacuolar invertase 1, GIN1 \\
\hline F6HJU7 & 0.667 & 1.854 & 3.1.2.2 & Ricinus communis & Stachyose synthase precursor \\
\hline EOCU00 & 0.805 & 0.542 & 3.5 & Ricinus communis & Aldo/keto reductase \\
\hline F6HHH7 & $N A^{*}$ & 1.714 & 3.5 & Glycine max & Putative aryl-alcohol dehydrogenase C977.14c-like \\
\hline D7TMQ2 & 0.666 & 0.783 & 6.1 & Vitis vinifera & Citrate synthase, glyoxysomal \\
\hline F6HJJ4 & 0.624 & 1.095 & 6.3 & Ricinus communis & Malate dehydrogenase \\
\hline A5BEJ8 & 0.524 & 1.328 & 6.3 & Vitis vinifera & Malate dehydrogenase, putative \\
\hline F6H9P9 & 0.455 & 1.618 & 11.1.1 & Camellia oleifera & Biotin carboxylase, CAC2 \\
\hline G3G8J7 & 0.425 & 0.696 & 12.1 .2 & Vitis vinifera & Nitrite reductase 1 \\
\hline D7SW04 & 0.744 & 0.519 & 13.1.1.2.1 & Petunia $\times$ hybrida & Prephenate aminotransferase \\
\hline A5ACX0 & 0.389 & 1.125 & 13.1.1.3.1 & Arabidopsis thaliana & Alanine-2-oxoglutarate aminotransferase 2 \\
\hline F6HA09 & 0.696 & 0.616 & 13.1.1.3.11 & Ricinus communis & Serine-pyruvate aminotransferase \\
\hline F6GST3 & 0.614 & 0.949 & 13.1.2.3.22 & Ricinus communis & Argininosuccinate synthase \\
\hline A5AGN5 & 0.896 & 0.157 & 13.1.4.1 & Catharanthus roseus & Ketol-acid reductoisomerase \\
\hline A5AFH5 & 0.397 & 0.825 & 13.1.5.3.1 & Vitis vinifera & Cysteine synthase \\
\hline F6HHQ7 & 1.652 & 0.553 & 13.2.3.5 & Hevea brasiliensis & Acetyl-CoA C-acetyltransferase \\
\hline F6H7l9 & 1.038 & 0.559 & 13.2.5.2 & Vitis vinifera & Aminomethyltransferase, mitochondrial-like \\
\hline A5BQ64 & 1.09 & 0.474 & 16.1.3.3 & Hevea brasiliensis & 2-methyl-6-phytylbenzoquinone methyltranferase \\
\hline A5BJL8 & 0.5 & 0.376 & 16.4.3.1 & Vitis vinifera & Cyanate hydratase \\
\hline D7SLA9 & 0.835 & 0.627 & 17.7.1.2 & Vitis vinifera & Lipoxygenase \\
\hline A5BEM6 & 1.25 & 0.643 & 19.3 & Ricinus communis & Glutamate-1-semialdehyde-2,1-aminomutase,GSA-AT \\
\hline A5BF85 & 1.526 & 0.635 & 19.8 & Ricinus communis & Coproporphyrinogen III oxidase, CPOX \\
\hline F6HM73 & 0.353 & 0.358 & 19.10 & Ricinus communis & Magnesium-chelatase subunit chll, chloroplast precursor \\
\hline F6HL38 & 0.2 & 1.02 & 23.3.1.3 & Glycine max & Uracil phosphoribosyltransferase-like \\
\hline A5B878 & 10.227 & 1.695 & 23.4.10 & Vitis vinifera & Nucleoside diphosphate kinase 1, NDPK1 \\
\hline F6HBJ7 & 0.813 & 0.602 & 23.4 .99 & Ricinus communis & Inorganic pyrophosphatase \\
\hline
\end{tabular}

*The proteins were not quantified under heat stress or subsequent recovery. 
NDPK1 may play an important role in grape leaves in response to heat stress.

\section{Proteins involved in glycolysis and TCA in mitochondrial respiration}

The regulation of the enzymes involved in respiratory carbon metabolism under heat stress has been a subject of debate. As shown in Table 4, there were six enzymes identified that are involved in glycolysis, which did not significantly change in expression level under heat stress while were downregulated after subsequent recovery. In addition, we found that five enzymes (dihydrolipoyl dehydrogenase, aconitase, malate dehydrogenase, succinatesemialdehyde dehydrogenase and carbonic anhydrase), which are involved in the TCA cycle, were dysregulated in the study. With the exception of aconitase, the expression of these enzymes was inhibited under heat stress and recovered to the control level or showed a slight increase after subsequent recovery. The above results suggest that the glycolysis pathway was not influenced, while the TCA cycle was inhibited by heat stress. We also hypothesize that during recovery, the TCA cycle recovereds to control levels to consume the excess pyruvic acid produced by glycolysis. Therefore, the glycolysis pathway may be more heat tolerant than the TCA cycle in respiration in grapevines.

\section{Conclusion}

This study provides a global look at the dysregulated proteins in grapevine leaves exposed to heat stress and after subsequent recovery using the iTRAQ technique. A total of 174 differentially expressed proteins were identified in response to heat stress and/or subsequent recovery. On the basis of these findings, we propose that some proteins related to the electron transport chain of photosynthesis, antioxidant enzymes, HSPs and the glycolysis pathway may play key roles in protecting grapevines from heat stress and enhancing their recovery capacity.

\section{Methods}

\section{Plant materials and treatments}

One-year old 'Cabernet sauvignon' ( $V$. vinifera L.) grapevine cuttings were planted in pots, then grown in a greenhouse at $70-80 \%$ relative humidity under a $18-25^{\circ} \mathrm{C}$, with the maximum photosynthetically active radiation (PAR) at approximately $1,000 \mu \mathrm{mol}$ photons $\mathrm{m}^{-2} \mathrm{~s}^{-1}$. When the sixth leaves (from bottom to top) of grapevines became mature, all grapevines were divided into two groups and acclimated for two days in a controlled environment room (70\% average relative humidity, 25/18 $(12 \mathrm{~h} / 12 \mathrm{~h})$ day/night cycle and PAR at $\left.800 \mu \mathrm{mol} \mathrm{m}^{-2} \mathrm{~s}^{-1}\right)$. On day three, the grapevines were subjected to the following treatments: (1) the plants of the control group were maintained at the optimal day/night temperature $\left(25^{\circ} \mathrm{C} /\right.$ $18^{\circ} \mathrm{C}$ ) in the above growth chamber; (2) the plants of the treatment group were exposed to $43^{\circ} \mathrm{C}$ from 9:30 to 15:30 (the conditions were the same as the control, except for temperature). The stressed grapevines were then allowed to recover at $25^{\circ} \mathrm{C}$ rapidly (from $43^{\circ} \mathrm{C}$ to $25^{\circ} \mathrm{C}$ in

Table 4 Proteins involved in respiration under heat stress and subsequent recovery

\begin{tabular}{|c|c|c|c|c|c|}
\hline \multirow{2}{*}{$\begin{array}{l}\text { Protein } \\
\text { accession }\end{array}$} & \multicolumn{2}{|c|}{ Fold change } & \multirow[t]{2}{*}{ Bin } & \multirow[t]{2}{*}{ Species } & \multirow[t]{2}{*}{ Description } \\
\hline & HS & RC & & & \\
\hline $\mathrm{F} 610 \mathrm{H} 8$ & 0.548 & 1.144 & 4.1 & Gossypium hirsutum & UDP-D-glucose pyrophosphorylase \\
\hline F6HFF7 & 0.931 & 1.93 & 4.2 & Ricinus communis & Phosphoglucomutase \\
\hline A5B118 & 1.356 & 0.481 & 4.7 & Vitis vinifera & Fructose-bisphosphate aldolase, FBA \\
\hline A5BX43 & 1.222 & 0.461 & 4.7 & Vitis vinifera & Fructose-bisphosphate aldolase, FBA, cytoplasmic isozyme 1-like \\
\hline F6GSG7 & 1.105 & 0.653 & 4.9 & Ricinus communis & Glyceraldehyde 3-phosphate dehydrogenase \\
\hline A5CAF6 & 1.017 & 0.5 & 4.10 & Vitis vinifera & Phosphoglycerate kinase, cytosolic-like \\
\hline A5BGC9 & 0.507 & 1.296 & 7.1 .3 & Vitis vinifera & 6-phosphogluconate dehydrogenase \\
\hline A5BDU8 & 0.537 & 0.938 & 8.1 .1 .3 & Vitis vinifera & Dihydrolipoamide dehydrogenase, putative \\
\hline D7TEL2 & 0.672 & 1.64 & 8.1 .3 & Ricinus communis & Aconitase \\
\hline F6HZKo & 0.499 & 1 & 8.2 .9 & Vitis vinifera & Malate dehydrogenase \\
\hline F6H9T6 & 0.466 & 0.972 & 8.2 .99 & Solanum lycopersicum & Succinic semialdehyde dehydrogenase \\
\hline A5BQL5 & 0.628 & 0.795 & 8.3 & Vitis vinifera & Chloroplast carbonic anhydrase \\
\hline A5C9C0 & 0.833 & 1.722 & 9.1 .2 & Ricinus communis & NADH-ubiquinone oxidoreductase flavoprotein \\
\hline A5ASP2 & 1.286 & 2.886 & 9.1 .2 & Ricinus communis & NADH-ubiquinone oxidoreductase 24 kD subunit \\
\hline D7TQ15 & $N A^{*}$ & 2.667 & 9.1 .2 & Solanum tuberosum & NADH:ubiquinone oxidoreductase-like \\
\hline D7SUP9 & $N A^{*}$ & 0.653 & 9.5 & Camellia sinensis & Ubiquinol-cytochrome C reductase complex \\
\hline
\end{tabular}

*The proteins were not quantified under heat stress or subsequent recovery. 
about $10 \mathrm{~min}$ ), then, all conditions were the same as the control until 9:30 h on Day 4. The fourth to sixth leaves (from bottom to up) of each plant were detached from each plant at 15:30 Day 3 (the end of the heat stress treatment) and 9:30 Day 4 (the day of recovery) (Additional file 8). Each biological replicate included three plants, and three replicates were used for both treatment and controls. Leaves were frozen in liquid nitrogen immediately and stored at $-80^{\circ} \mathrm{C}$ for further analysis.

\section{Analysis of chlorophyll fluorescence parameters}

The chlorophyll $a$ fluorescence transient (O-J-I-P test) was measured by a Handy Plant Efficiency Analyzer after the leaves adapted for $15 \mathrm{~min}$ in the dark. The chlorophyll $a$ fluorescence transient was induced by a saturating photon flux density at $3000 \mu \mathrm{mol}$ photons $\mathrm{m}^{-2} \mathrm{~s}^{-1}$, provided by an array of six light-emitting diodes (peak $650 \mathrm{~nm}$ ). The fluorescence signals were recorded within a time span from $10 \mu$ s to $1 \mathrm{~s}$, with a data acquisition rate of $10 \mu \mathrm{s}$ for the first $2 \mathrm{~ms}$ and every $1 \mathrm{~ms}$ thereafter. The following data from the original measurements were used: $F_{\mathrm{k}}$ : fluorescence intensity at $300 \mu \mathrm{s}$ [required for calculation of the initial slope $(\mathrm{M})$ of the relative variable fluorescence $(\mathrm{V})$ kinetics and $\left.\mathrm{W}_{\mathrm{k}}\right] ; F_{\mathrm{j}}$ : the fluorescence intensity at $2 \mathrm{~ms}$ (the J-step); $F_{\mathrm{i}}$ : the fluorescence intensity at $30 \mathrm{~ms}$ (the I-step); $F_{\mathrm{m}}$ : maximal fluorescence intensity (the P-step). The derived parameters are as follows: $F_{\mathrm{o}}$ : fluorescence intensity at $50 \mu \mathrm{s}$; the parameter $\mathrm{W}_{\mathrm{k}}$ on donor side of photosystem II (PSII), represents the damage to OEC, $\mathrm{W}_{\mathrm{k}}=\left(F_{\mathrm{k}}-F_{\mathrm{o}}\right) /\left(F_{\mathrm{j}}-F_{\mathrm{o}}\right)$; the parameter $\mathrm{RC}_{\mathrm{QA}}$ on reaction center of PSII, represents the density of $\mathrm{Q}_{\mathrm{A}}$-reducing reaction centers, $\mathrm{RC}_{\mathrm{QA}}=\varphi_{\mathrm{Po}} \times\left(\mathrm{V}_{\mathrm{j}} / \mathrm{M}_{\mathrm{o}}\right) \times\left(\mathrm{ABS} / \mathrm{CS}_{\mathrm{m}}\right)$; the parameter $F_{\mathrm{v}} / F_{\mathrm{m}}$ on acceptor side of PSII, represents maximum quantum yield of primary photochemistry at $\mathrm{t}=0$; the parameter $\varphi_{\mathrm{Eo}}$ on acceptor side of PSII, represents quantum yield for electron transport (at $\mathrm{t}=0), \varphi_{\mathrm{Eo}}=\mathrm{ET}_{\mathrm{o}} /$ $\mathrm{ABS}=\left(F_{\mathrm{m}}-F_{\mathrm{j}}\right) / F_{\mathrm{m}}$. The calculation and derivation of a range of new parameters from O-J-I-P transients is shown in Additional file 9. Five independent replicates were used in both treatments and controls respectively, and each replicate consisted of a plant. The chlorophyll $a$ fluorescence transient was measured on the same plants under heat stress and subsequent recovery.

\section{Measurement of thiobarbituric acidreactivesubstances (TBARS)}

The content of TBARS was determined according to the methods of Heath and Packer [80] with minor modifications. About $1 \mathrm{~g}$ of frozen leaves were homogenized in $0.5 \%$ thiobarbituric acid and $20 \%$ trichloroacetic acid. After heating for $30 \mathrm{~min}$ at $95^{\circ} \mathrm{C}$, samples were cooled quickly in an ice-water bath. Air bubbles were then removed from each tube by shaking, and samples were centrifuged at $14,000 \mathrm{rpm}$ for 20 minutes at $20^{\circ} \mathrm{C}$. The absorbance of the supernatant was read at $532 \mathrm{~nm}$, corrected for nonspecific turbidity by subtracting the absorbance at $600 \mathrm{~nm}$. The amount of TBARS was calculated by using an extinction coefficient of $155 \mathrm{mM}^{-1} \mathrm{~cm}^{-1}$.

\section{Protein extraction}

Total protein was extracted using the cold-acetone method. The three biological replicates of the frozen grape leaves were pooled for iTRAQ analysis [81,82], and $10 \% \mathrm{~m} / \mathrm{m}$ polyvinyl polypyrrolidone (PVPP) were transferred to a mortar with liquid nitrogen and ground until a fine powder was obtained. Approximately $500 \mathrm{mg}$ of the ground up leaf powder was combined with $4 \mathrm{ml}$ of $10 \% \mathrm{~m} / \mathrm{v}$ trichloroacetic acid (TCA) in acetone to each sample, and the samples were incubated at $-20^{\circ} \mathrm{C}$ for $2 \mathrm{~h}$. The samples were then centrifuged at 20,000 $\mathrm{g}$ for $30 \mathrm{~min}$ at $4^{\circ} \mathrm{C}$. The supernatant was discarded without disturbing the pellets. In order to reduce acidity, the pellets were washed with acetone and incubated at $-20^{\circ} \mathrm{C}$ for $30 \mathrm{~min}$, and centrifuged at $20,000 \mathrm{~g}$ for $30 \mathrm{~min}$ at $4^{\circ} \mathrm{C}$. The washing step with acetone was repeated several times until the pellets were white. The dried pellets were lysed with $1 \mathrm{ml}$ protein extraction reagent [ $8 \mathrm{M}$ urea, $30 \mathrm{mM}$ HEPES, $1 \mathrm{mM}$ PMSF, $2 \mathrm{mM}$ EDTA and $10 \mathrm{mM}$ DTT]. The pellets were then dissolved by ultrasound (pulse on $2 \mathrm{~s}$, pulse off $3 \mathrm{~s}$, power $180 \mathrm{w}$ ) for five minutes. After dissolution, the solution was centrifuged at $20,000 \mathrm{~g}$ for $30 \mathrm{~min}$ at $4{ }^{\circ} \mathrm{C}$ to remove nonsoluble impurities. Proteins were reduced with $10 \mathrm{mM}$ DTT at $56^{\circ} \mathrm{C}$ for $1 \mathrm{~h}$ and alkylated immediately by $55 \mathrm{mM}$ iodoacetamide (IAM) in the dark at room temperature for $1 \mathrm{~h}$. The treated proteins were precipitated in acetone at $-20^{\circ} \mathrm{C}$ for $3 \mathrm{~h}$. After centrifugation at $20,000 \mathrm{~g}$ for $20 \mathrm{~min}$ at $4^{\circ} \mathrm{C}$, the pellets were resuspended and ultrasonicated in pre-chilled 50\% TEAB buffer with $0.1 \%$ SDS and dissolved by ultrasound. The proteins were regained after centrifugation at $2000 \mathrm{~g}$ and protein concentration was determined by the Bradford assay using BSA as a standard.

\section{Digestion and ITRAQ labeling}

Total of $100 \mu \mathrm{g}$ protein in TEAB buffer was incubated with $3.3 \mu \mathrm{g}$ of trypsin $(1 \mu \mathrm{g} / \mu \mathrm{l})$ (Promega, Madison, WI, USA) at $37^{\circ} \mathrm{C}$ for $24 \mathrm{~h}$ in a sealed tube. The tryptic peptides were lyophilized and dissolved in the 50\% TEAB buffer and the trypsin digested samples were analyzed using MALDI-TOF/TOF to ensure complete digestion. The protocol of iTRAQ labelling was followed the company manual. The tryptic peptides were incubated with 8-plex iTRAQ labeling kit (AB Sciex, Foster City, CA, USA) (116 for HS-CK; 121 for HS-TR; 114 for RC-CK; 118 for RC-TR) for $2 \mathrm{~h}$ at room temperature, which was dissolved in $70 \mu \mathrm{l}$ isopropanol. 
Peptide fractionation by strong cation exchange (SCX)

The labeled samples were fractionated using an HPLC system (Shimadzu, Kyoto, Japan) connected to an SCX column (Luna $5 \mathrm{u}$ column, $4.6 \mathrm{~mm} \times 250 \mathrm{~mm}, 5 \mu \mathrm{m}$, $100 \AA$ A; Phenomenex, Torrence, CA). The retained peptides were eluted using Buffer A $\left(10 \mathrm{mM} \mathrm{KH} \mathrm{KO}_{4}\right.$ in an aqueous solution of $25 \%$ acetonitrile and acidified to a $\mathrm{pH}$ of 3.0 with $\mathrm{H}_{3} \mathrm{PO}_{4}$ ) and Buffer B, where Buffer B was composed of Buffer A with $2 \mathrm{M} \mathrm{KCl}$. The fractions were collected in $1.5 \mathrm{ml}$ microfuge tubes with flow rate at $1 \mathrm{ml} / \mathrm{min}$. The following chromatographic gradient was applied: $0 \sim 25$ min 100\% Buffer A; $25 \sim 26$ min 5\% Buffer B; 26 46 min 5-30\% Buffer B; $46 \sim 51$ min 30-50\% Buffer B, 51-56 min 50\% Buffer B; 56-61 min increasing to $100 \%$ Buffer B. All solutions used were centrifuged again at $20,000 \mathrm{~g}$ for $30 \mathrm{~min}$ at $4^{\circ} \mathrm{C}$. Fraction collection started 26 min after the injection with a sample collected every $1 \mathrm{~min}$ to obtain a total of 38 fractions. For fractions containing a high concentration of salt, an additional step was used to remove the salt with Strata-X $33 \mathrm{u}$ polymeric reversed phase column (Phenomenex). Eluted fractions were dried in a vacuum concentrator, and each fraction was dissolved in $0.1 \%$ formic acid solution prior to reversed-phase nano-LC-tandem mass spectrometry (LC-MS/MS).

\section{Reverse-Pphase nano liquid xhromatography tandem MS} The SCX peptide fractions were pooled together to obtain 10 final fractions, to reduce the number of samples and collection time. A $10 \mu \mathrm{l}$ sample from each fraction was injected twice to the Proxeon Easy Nano-LC system. Peptides were separated on $\mathrm{C} 18$ analytical reverse phase column $(100 \mathrm{~mm} \times 75 \mathrm{~mm}, 300 \AA, 5 \mu \mathrm{m})$ at a flow rate of $400 \mathrm{nl} / \mathrm{min}$ and a linear LC gradient profile was used to elute peptides from the column. The fractions were then analyzed using a hybrid Quadrupole/Time-offlight MS (Triple-TOF 5600, AB SCIEX, USA) with nano electrospray ion source. The MS/MS scans from 50-2000 m/z were recorded. Nitrogen was used as the collision gas. The ionization tip voltage and interface temperature were set at $1250 \mathrm{~V}$ and $150^{\circ} \mathrm{C}$, respectively.

\section{Database search and protein quantification}

All the mass spectral data were collected using Micro TOF (AB5600, Applied Biosystems) control software, and processed and analyzed using Data Analysis 4.0. The database of uniprot grape (12/1/2011, 55416 sequences) was downloaded (http://www.uniprot.org/) and integrated into the Mascot search engine version 2.3.01 by its database maintenance unit. All parameters were set as follows: specifying trypsin as the digestion enzyme, cysteine carbamido methylation as fixed modification, iTRAQ 8-Plex on N-terminal residue, iTRAQ 8-Plex on tyrosine, iTRAQ 8-Plex on lysine, glutamine as pyroglutamic acid and oxidation on methionine as the variable modification. The tolerance settings for peptide identification in Mascot searches were set at 0.05 Da for MS and 0.05 Da for MS/ MS. The maximum missed cleavages were set as 1 . Finally, the Mascot search results were exported into a DAT file, quantified using Mascot 2.3.01 with the following criterias: protein ratio type $=$ median, minimum unique peptides $=1$, peptide threshold type $=$ at least homolog. Peptides were not quantified for the following reasons: peptide score was too low, or the deviation was too large. The final ratios of protein were then normalized by taking the median of all the proteins quantified. All quantified proteins are listed in Additional file 10.

\section{Functional classification, enrichment analysis and subcellular localization}

Differentially expressed proteins functionally classified according to MapMan ontology [83]. Enrichment analysis was conducted using the Singular Enrichment Analysis (SEA) tool in the agriGO toolkit [84]. Uniprot IDs were submitted to the SEA tool as the query list and suggested backgrounds were as the select reference. Under advanced options the statistical test method chosen was Fisher, the multi-test method was Yekutieli (FDR under dependency), the significance level was 0.05 , and the gene ontology type chosen was Plant GO slim. Subcellular localizations of proteins were determined using TargetP [85].

\section{Additional files}

Additional file 1: The homologs of unknown proteins. BLASTP

(http://www.ncbi.nlm.nih.gov/BLAST/) was used to search for homologs of the unknown proteins.

Additional file 2: The functional categories of the 174 differentially expressed proteins according to MapMan ontology.

Additional file 3: Differentially expressed proteins under heat stress and subsequent recovery.

Additional file 4: Differentially expressed proteins only response to heat stress.

Additional file 5: Differentially expressed proteins only response to recovery from heat stress.

Additional file 6: The temperature conditions of grapevine in the present study.

Additional file 7: Enrichment analysis against agriGo of grapevine proteins under heat stress and/or subsequent recovery.

Additional file 8: File containing the GO-terms annotated by agriGO for the proteins differentially expressed under heat stress and/or subsequent recovery.

Additional file 9: Summary of parameters, formulae and their description using data extracted from chlorophyll $a$ fluorescence transient (O-J-I-P test).

Additional file 10: Detailed information of the identified proteins under heat stress and/or subsequent recovery.

\section{Abbreviations}

APX: Ascorbate peroxidase; CAT: Catalase; CK: Control; FBA: Fructose bisphosphate aldolase; HS: Heat stress; HSP: Heat shock protein; ITRAQ: Isobaric tags for relative and absolute quantitation; 
LHC: Light-harvesting chlorophyll-protein complex; NDPK: Nucleoside diphosphate kinase; OEC: Oxygen evolution complex; PS: Photosystem; RC: Recovery; SOD: Superoxide dismutase; TBARS: Thiobarbituric acidreactivesubstances; TCA: Tricarboxylic acid cycle; TR: Treatment.

\section{Competing interests}

The authors declare that they have no competing interests.

\section{Authors' contributions}

GTL and LJW designed the study, performed the proteomic experiments and wrote the manuscript. LM assisted with experiment design, proteomic experiments, data analysis and manuscript writing. WD, JHL, HGX and BFY assisted to conduct the measurement of TBARS and chlorophyll fluorescence parameters. XQY performed the blast analysis and wrote this part. BCW and $\mathrm{SHL}$ revised the draft of the manuscript. All authors read, revised and approved the final manuscript.

\section{Acknowledgements}

This work was supported by the National Natural Science Foundation of China (No. 30771758 and 31130047).

\section{Author details}

'Key laboratory of Plant Resources and Beijing Key Laboratory of Grape Science and Enology, Institute of Botany, Chinese Academy of Sciences, Beijing 100093, P. R., China. ${ }^{2}$ University of China Academy of Sciences, Beijing 100049, P. R., China. ${ }^{3}$ Key Laboratory of Photobiology, Institute of Botany, Chinese Academy of Sciences, Beijing 100093, P. R., China. ${ }^{4}$ Beijing Computing Center, Beijing 100094, P. R. China. ${ }^{5}$ Key laboratory of Plant Germplasm Enhancement and Specialty Agriculture, Wuhan Botany Garden, Chinese Academy of Sciences, Wuhan 430074, P. R., China.

Received: 18 February 2014 Accepted: 17 April 2014

Published: 28 April 2014

\section{References}

1. Wahid A, Gelani S, Ashraf M, Foolad M: Heat tolerance in plants: An overview. Environ Exp Bot 2007, 61(3):199-223.

2. Lobell DB, Burke MB, Tebaldi C, Mastrandrea MD, Falcon WP, Naylor RL: Prioritizing climate change adaptation needs for food security in 2030. Science 2008, 319(5863):607-610.

3. Howarth C: Genetic improvements of tolerance to high temperature. In Abiotic Stresses: Plant Resistance through Breeding and Molecular Approaches. New York: Howarth Press Inc; 2005.

4. Bokszczanin KL, Solanaceae Pollen Thermotolerance Initial Training Network C, Fragkostefanakis S: Perspectives on deciphering mechanisms underlying plant heat stress response and thermotolerance. Front Plant Sci 2013, 4:315.

5. Govindjee: Sixty-three years since Kautsky: chlorophyll $a$ fluorescence. Aust J Plant Physiol 1995, 22(2):131-160.

6. Stirbet A: On the relation between the Kautsky effect (chlorophyll $a$ fluorescence induction) and photosystem II: basics and applications of the OJIP fluorescence transient. J Photochem Photobiol 2011 104(1):236-257

7. Smertenko A, Draber P, Viklicky V, Opatrny Z: Heat stress affects the organization of microtubules and cell. Plant Cell Environ 1997, 20:1534-1542.

8. Schöffl F, Prandl R, Reindl A: Molecular responses to heat stress. In Molecular Responses to Cold, Drought, Heat and Salt Stress in Higher Plants. Austin, Texas: RG Landes Co; 1999:83-93.

9. Lee DG, Ahsan N, Lee SH, Kang KY, Bahk JD, Lee IJ, Lee BH: A proteomic approach in analyzing heat-responsive proteins in rice leaves. Proteomics 2007, 7(18):3369-3383.

10. Lin SK, Chang MC, Tsai YG, Lur HS: Proteomic analysis of the expression of proteins related to rice quality during caryopsis development and the effect of high temperature on expression. Proteomics 2005, 5(8):2140-2156.

11. Skylas DJ, Cordwell SJ, Hains PG, Larsen MR, Basseal DJ, Walsh BJ, Blumenthal C, Rathmell W, Copeland L, Wrigley CW: Heat shock of wheat during grain filling: proteins associated with heat-tolerance. J Cereal Sci 2002, 35(2):175-188.
12. Majoul T, Bancel E, Triboi E, Ben Hamida J, Branlard G: Proteomic analysis of the effect of heat stress on hexaploid wheat grain: characterization of heat-responsive proteins from total endosperm. Proteomics 2003, 3(2):175-183.

13. Sule A, Vanrobaeys F, Hajos G, Van Beeumen J, Devreese B: Proteomic analysis of small heat shock protein isoforms in barley shoots. Phytochemistry 2004, 65(12):1853-1863.

14. Ferreira S, Hjerno K, Larsen M, Wingsle G, Larsen P, Fey S, Roepstorff P, Pais MS: Proteome profiling of Populus euphratica Oliv. Upon heat stress. Ann Bot 2006, 98(2):361-377.

15. Valcu C-M, Lalanne C, Plomion C, Schlink K: Heat induced changes in protein expression profiles of Norway spruce (Picea abies) ecotypes from different elevations. Proteomics 2008, 8(20):4287-4302.

16. Ng ZX, Chua KH, Kuppusamy UR: Proteomic analysis of heat treated bitter gourd (Momordica charantia L. var. Hong Kong Green) using 2D-DIGE. Food Chem 2014, 148:155-161.

17. Zieske LR: A perspective on the use of iTRAQ reagent technology for protein complex and profiling studies. J Exp Bot 2006, 57(7):1501-1508

18. Wu WW, Baek GWSJ, Shen R-F: Comparative study of three proteomic quantitative metheods, DIGE, CICAT, and ITRAQ, using 2D Gel- or LC- MALDI TOF/TOF. J Proteome Res 2005, 5:651-658.

19. Aggarwal $K$, Choe LH, Lee KH: Shotgun proteomics using the iTRAQ isobaric tags. Brief Funct Genomic Proteomic 2006, 5(2):112-120.

20. Ross PL, Huang YN, Marchese JN, Williamson B, Parker K, Hattan S, Khainovski N, Pillai S, Dey S, Daniels S, Purkayastha S, Juhasz P, Martin S, Bartlet-Jones M, He F, Jacobson A, Pappin DJ: Multiplexed protein quantitation in Saccharomyces cerevisiae using amine-reactive isobaric tagging reagents. Mol Cell Proteomics 2004, 3(12):1154-1169.

21. Vivier MA, Pretorius IS: Genetically tailored grapevines for the wine industry. Trends Biotechnol 2002, 20(11):472-478.

22. Sepulveda G, Kliewer WM: Stomatal response of three grapevine cultivars (Vitis vinifera L.) to high temperature. Am J Enol Vitic 1986, 37:44-52.

23. Howell GS: Sustainable grape productivity and the growth-yield relationship: A review. Am J Enol Vitic 2001, 52(3):165-174.

24. Caprio JM, Quamme HA: Weather conditions associated with grape production in the Okanagan Valley of British Columbia and potential impact of climate change. Can J Plant Sci 2002, 82(4):755-763.

25. Wang $\sqcup$, Li SH: Salicylic acid-induced heat or cold tolerance in relation to $\mathrm{Ca}(2+)$ homeostasis and antioxidant systems in young grape plants. Plant Sci 2006, 170(4):685-694.

26. Mori K, Goto-Yamamoto N, Kitayama M, Hashizume K: Loss of anthocyanins in red-wine grape under high temperature. J Exp Bot 2007, 58(8):1935-1945.

27. Wang $\sqcup$, Loescher W, Duan W, Li W-D, Yang S-H, Li S-H: Heat acclimation induced acquired heat tolerance and cross adaptation in different grape cultivars: relationships to photosynthetic energy partitioning. Funct Plant Biol 2009, 36(6):516-526

28. Luo HB, Ma L, Xi HF, Duan W, Li SH, Loescher W, Wang JF, Wang LJ: Photosynthetic responses to heat treatments at different temperatures and following recovery in grapevine (Vitis amurensis L) leaves. PLoS One 2011, 6(8):e23033.

29. Liu GT, Wang JF, Grant C, Dai ZW, Duan W, Xu HG, Wu BH, Fan PG, Wang LJ, Li SH: Transcriptomic analysis of grape (Vitis vinifera L.) leaves during and after recovery from heat stress. BMC Plant Biol 2012, 12:174.

30. Agrawal GK, Rakwal R: Rice proteomics: A cornerstone for cereal food crop proteomes. Mass Spectrom Rev 2006, 25(1):1-53.

31. Martinez-Esteso MJ, Selles-Marchart S, Lijavetzky D, Pedreno MA, BruMartinez R: A DIGE-based quantitative proteomic analysis of grape berry flesh development and ripening reveals key events in sugar and organic acid metabolism. J Exp Bot 2011, 62(8):2521-2569.

32. Basha SM, Mazhar H, Vasanthaiah HKN: Proteomics approach to identify unique xylem sap proteins in pierce's disease-tolerant Vitis species. App/ Biochem Biotechnol 2010, 160(3):932-944.

33. Martinez-Esteso MJ, Casado-Vela J, Selles-Marchart S, Elortza F, Pedreno MA, Bru-Martinez R: iTRAQ-based profiling of grape berry exocarp proteins during ripening using a parallel mass spectrometric method. Mol Biosyst 2011, 7(3):749-765

34. Sharathchandra RG, Stander C, Jacobson D, Ndimba B, Vivier MA: Proteomic analysis of grape berry cell cultures reveals that developmentally regulated ripening related processes can be studied using cultured cells. PLoS One 2011, 6(2):e14708 
35. Zamboni A, Di Carli M, Guzzo F, Stocchero M, Zenoni S, Ferrarini A, Tononi P, Toffali K, Desiderio A, Lilley KS, Pe ME, Benvenuto E, Delledonne M, Pezzotti M: Identification of putative stage-specific grapevine berry biomarkers and omics data integration into networks. Plant Physiol 2010, 154(3):1439-1459.

36. Zhao FX, Chen LH, Perl A, Chen SW, Ma HQ: Proteomic changes in grape embryogenic callus in response to Agrobacterium tumefaciens-mediated transformation. Plant Sci 2011, 181(4):485-495.

37. Margaria P, Palmano: Response of the Vitis vinifera L. Cv. 'Nebbiolo' proteome to flavescence doree phytoplasma infection. Proteomics 2011 $11(2): 212-224$

38. Giribaldi M, Purrotti M, Pacifico D, Santini D, Mannini F, Caciagli P, Rolle L, Cavallarin L, Giuffrida MG, Marzachi C: A multidisciplinary study on the effects of phloem-limited viruses on the agronomical performance and berry quality of Vitis vinifera cv. Nebbiolo. J Proteomics 2011, 75(1):306-315.

39. Marsh E, Alvarez S, Hicks LM, Barbazuk WB, Qiu W, Kovacs L, Schachtman D: Changes in protein abundance during powdery mildew infection of leaf tissues of Cabernet Sauvignon grapevine (Vitis vinifera L). Proteomics 2010, 10(10):2057-2064.

40. Cobos R, Barreiro C, Maria Mateos R, Coque J-JR: Cytoplasmic- and extracellular-proteome analysis of Diplodia seriata: a phytopathogenic fungus involved in grapevine decline. Proteome Sci 2010, 8:46.

41. Grimplet J, Wheatley MD, Jouira HB, Deluc LG, Cramer GR, Cushman JC: Proteomic and selected metabolite analysis of grape berry tissues under well-watered. Proteomics 2009, 9(9):2503-2528.

42. Vincent $D$, Ergul A, Bohlman MC, Tattersall EAR, Tillett RL, Wheatley MD, Woolsey R, Quilici DR, Joets J, Schlauch K, Schooley DA, Cushman JC Cramer GR: Proteomic analysis reveals differences between Vitis vinifera L. cv. Chardonnay and cv. Cabernet Sauvignon and their responses to water deficit and salinity. J Exp Bot 2007, 58(7):1873-1892.

43. Jellouli N, Ben Jouira H, Skouri H, Ghorbel A, Gourgouri A, Mliki A: Proteomic analysis of Tunisian grapevine cultivar Razegui under salt stress. J Plant Physiol 2008, 165(5):471-481.

44. Galmes J, Medrano H, Flexas J: Photosynthetic limitations in response to water stress and recovery in Mediterranean plants with different growth forms. New Phytol 2007, 175(1):81-93.

45. Sengupta D, Kannan M, Reddy AR: A root proteomics-based insight reveals dynamic regulation of root proteins under progressive drought stress and recovery in Vigna radiata (L.) Wilczek. Planta 2011, 233(6):1111-1127.

46. Mirzaei M, Pascovici D, Atwell BJ, Haynes PA: Differential regulation of aquaporins, small GTPases and V-ATPases proteins in rice leaves subjected to drought stress and recovery. Proteomics 2012, 12(6):864-877.

47. Salavati A, Khatoon A, Nanjo Y, Komatsu S: Analysis of proteomic changes in roots of soybean seedlings during recovery after flooding. $J$ Proteomics 2012, 75(3):878-893.

48. Vinocur B, Altman A: Recent advances in engineering plant tolerance to abiotic stress: achievements and limitations. Curr Opin Biotechnol 2005, 16(2):123-132.

49. Strasser BJ: Donor side capacity of photosystem II probed by chlorophyll a fluorescence transients. Photosynth Res 1997, 52:147-155.

50. Nguyen THN, Brechenmacher L, Aldrich JT, Clauss TR, Gritsenko MA Hixson KK, Libault M, Tanaka K, Yang F, Yao Q, Pas ² a-Tolic L, Xu D, Nguyen HT, Stacey G: Quantitative phosphoproteomic analysis of soybean root hairs inoculated with bradyrhizobium japonicum. Mol Cell Proteomics 2012, 11:1140-1155.

51. Tolin S, Arrigoni G, Trentin AR, Veljovic-Jovanovic S, Pivato M, Zechman B, Masi A: Biochemical and quantitative proteomics investigations in Arabidopsis ggt1 mutant leaves reveal a role for the gammaglutamyl cycle in plant's adaptation to environment. Proteomics 2013, 13(12-13):2031-2045.

52. Tolin S, Arrigoni G, Moscatiello R, Masi A, Navazio L, Sablok G, Squartini A: Quantitative analysis of the naringenin-inducible proteome in Rhizobium leguminosarum by isobaric tagging and mass spectrometry. Proteomics 2013, 13(12-13):1961-1972

53. Wang L, Liang W, Xing J, Tan F, Chen Y, Huang L, Cheng CL, Chen W: Dynamics of chloroplast proteome in salt-stressed mangrove Kandelia candel (L) Druce. J Proteome Res 2013, 12(11):5124-5136.

54. Srivastava A, Guisse B, Greppin H, Strasser RJ: Regulation of antenna structure and electron transport in photosystem II of Pisum sativum under elevated temperature probed by the fast polyphasic chlorophyll $a$ fluorescence transient: OKJIP. Biochim Biophys Acta 1997, 1320:95-106.

55. Camejo D, Rodriguez P, Morales A, Dell'Amico JM, Torrecillas A, Alarcon JJ: High temperature effects on photosynthetic activity of two tomato cultivars with different heat susceptibility. J Plant Physiol 2005, 162(3):281-289

56. Efeoglu B, Terzioglu S: Photosynthetic responses of two wheat varieties to high temperature. EurAsia J BioSci 2009, 3:97-106.

57. Roose $J$, Wegener KM, Pakrasi HB: The extrinsic proteins of photosystem II. Photosynth Res 2007, 92(3):369-387.

58. Suorsa M, Sirpio S, Allahverdiyeva Y, Paakkarinen V, Mamedov F Styring S, Aro EM: PsbR, a missing link in the assembly of the oxygen-evolving complex of plant photosystem II. J Biol Chem 2006, 281(1):145-150.

59. Ashraf $M$, Harris PJC: Photosynthesis under stressful environments: An overview. Photosynthetica 2013, 51(2):163-190

60. Amunts A, Drory O, Nelson N: The structure of a plant photosystem I supercomplex at 3.4 angstrom resolution. Nature 2007, 447(7140):58-63.

61. Vierling E: The roles of heat shock proteins in plants. Annu Rev Plant Biol 1991, 42(1):579-620.

62. Frydman J: Folding of newly translated proteins in vivo: The role of molecular chaperones. Annu Rev Biochem 2001, 70:603-647.

63. Buchner J: Hsp90 \& Co. - a holding for folding. Trends Biochem Sci 1999 , 24(4):136-141.

64. Young JC, Moarefi I, Hartl FU: Hsp90: a specialized but essential proteinfolding tool. J Cell Biol 2001, 154(2):267-274.

65. Richter K, Buchner J: Hsp90: Chaperoning signal transduction. J Cell Physiol 2001, 188(3):281-290.

66. Pratt WB, Krishna P, Olsen LJ: Hsp90-binding immunophilins in plants: the protein movers. Trends Plant Sci 2001, 6(2):54-58.

67. Boston RS, Viitanen PV, Vierling E: Molecular chaperones and protein folding in plants. Plant Mol Biol 1996, 32(1-2):191-222.

68. Kosova K, Vitamvas P, Prasil IT, Renaut J: Plant proteome changes under abiotic stress - Contribution of proteomics studies to understanding plant stress response. J Proteomics 2011, 74(8):1301-1322.

69. Vierling E: The role of heat-shock proteins in plants. Annu Rev Plant Physiol Plant Mol Biol 1991, 42:579-620.

70. Waters ER, Lee GJ, Vierling E: Evolution, structure and function of the small heat shock proteins in plants. J Exp Bot 1996, 47(296):325-338.

71. Wang W, Vinocur B, Shoseyov O, Altman A: Role of plant heat-shock proteins and molecular chaperones in the abiotic stress response. Trends Plant Sci 2004, 9(5):244-252.

72. Yamaguchi-Shinozaki K, Kasuga M, Liu Q, Nakashima K, Sakuma Y, Abe H, Shinwari ZK, Seki M, Shinozaki K: Biological mechanisms of drought stress response. JIRCAS Working Report 2002, 23:1-8.

73. Palmblad M, Mills DJ, Bindschedler LV: Heat-shock response in Arabidopsis thaliana explored by multiplexed quantitative proteomics using differential metabolic labeling. J Proteome Res 2008, 7(2):780-785.

74. Neta-Sharir I, Isaacson T, Lurie S, Weiss D: Dual role for tomato heat shock protein 21: protecting photosystem II from oxidative stress and promoting color changes during fruit maturation. Plant Cell 2005, 17(6):1829-1838

75. Xu C, Huang B: Differential proteomic response to heat stress in thermal Agrostis scabra and heat-sensitive Agrostis stolonifera. Physiol Plantarum 2010, 139(2):192-204.

76. Serrato AJ, Perez-Ruiz JM, Cejudo FJ: Cloning of thioredoxin h reductase and characterization of the thioredoxin reductase-thioredoxin $h$ system from wheat. Biochem J 2002, 367:491-497.

77. Gelhaye E, Rouhier N, Navrot N, Jacquot JP: The plant thioredoxin system. Cell Mol Life Sci 2005, 62(1):24-35.

78. Fukamatsu Y, Yabe N, Hasunuma K: Arabidopsis NDK1 is a component of ROS signaling by interacting with three catalases. Plant Cell Physiol 2003, 44(10):982-989.

79. Yoshida Y, Hasunuma K: Light-dependent subcellular localization of nucleoside diphosphate kinase-1 in Neurospora crassa. FEMS Microbiol Lett 2006, 261(1):64-68.

80. Heath RL, Packer L: Photoperoxidation in isolated chloroplasts I. kinetics and stoichiometry of fatty acid peroxidation. Arch Biochem Biophys 1968, 125:189-198.

81. Qiao J, Huang S, Te R, Wang J, Chen L, Zhang W: Integrated proteomic and transcriptomic analysis reveals novel genes and regulatory 
mechanisms involved in salt stress responses in Synechocystis sp. PCC 6803. Appl Microbiol Biotechnol 2013, 97(18):8253-8264.

82. Martinez-Esteso MJ, Vilella-Anton MT, Pedreno MA, Valero ML, Bru-Martinez R: iTRAQ-based protein profiling provides insights into the central metabolism changes driving grape berry development and ripening. BMC Plant Biol 2013, 13(1):167.

83. Usadel B, Poree F, Nagel A, Lohse M, Czedik-Eysenberg A, Stitt M: A guide to using MapMan to visualize and compare Omics data in plants: a case study in the crop species, Maize. Plant Cell Environ 2009, 32(9):1211-1229.

84. Du Z, Zhou X, Ling Y, Zhang Z, Su Z: agriGO: a GO analysis toolkit for the agricultural community. Nucleic Acids Res 2010, 38(Web Server issue):W64-W70.

85. Emanuelsson O, Nielsen $\mathrm{H}$, Brunak S, Heijne G: Predicting subcellular localization of proteins based on their $\mathrm{N}$-terminal amino acid sequence. J Mol Biol 2000, 300:1005-1016

doi:10.1186/1471-2229-14-110

Cite this article as: Liu et al.: Differential proteomic analysis of grapevine leaves by iTRAQ reveals responses to heat stress and subsequent recovery. BMC Plant Biology 2014 14:110.

\section{Submit your next manuscript to BioMed Central and take full advantage of:}

- Convenient online submission

- Thorough peer review

- No space constraints or color figure charges

- Immediate publication on acceptance

- Inclusion in PubMed, CAS, Scopus and Google Scholar

- Research which is freely available for redistribution 